NATIONAL LABORATORY

\title{
RadSTraM: Radiological Source Tracking and Monitoring, Phase II Final Report
}

\section{January 27, 2007}

\author{
Prepared by \\ T. A. Warren \\ R. M. Walker \\ D. E. Hill \\ I. G. Gross \\ C. M. Smith \\ R. K. Abercrombie
}

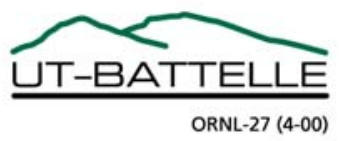




\title{
DOCUMENT AVAILABILITY
}

Reports produced after January 1, 1996, are generally available free via the U.S. Department of Energy (DOE) Information Bridge.

Web site http://www.osti.gov/bridge

Reports produced before January 1, 1996, may be purchased by members of the public from the following source.

\author{
National Technical Information Service \\ 5285 Port Royal Road \\ Springfield, VA 22161 \\ Telephone 703-605-6000 (1-800-553-6847) \\ TDD 703-487-4639 \\ Fax 703-605-6900 \\ E-mail info@ntis.gov \\ Web site http://www.ntis.gov/support/ordernowabout.htm
}

Reports are available to DOE employees, DOE contractors, Energy Technology Data Exchange (ETDE) representatives, and International Nuclear Information System (INIS) representatives from the following source.

Office of Scientific and Technical Information

P.O. Box 62

Oak Ridge, TN 37831

Telephone 865-576-8401

Fax 865-576-5728

E-mail reports@osti.gov

Web site http://www.osti.gov/contact.html

This report was prepared as an account of work sponsored by an agency of the United States Government. Neither the United States Government nor any agency thereof, nor any of their employees, makes any warranty, express or implied, or assumes any legal liability or responsibility for the accuracy, completeness, or usefulness of any information, apparatus, product, or process disclosed, or represents that its use would not infringe privately owned rights. Reference herein to any specific commercial product, process, or service by trade name, trademark, manufacturer, or otherwise, does not necessarily constitute or imply its endorsement, recommendation, or favoring by the United States Government or any agency thereof. The views and opinions of authors expressed herein do not necessarily state or reflect those of the United States Government or any agency thereof. 


\title{
RADSTRAM: RADIOLOGICAL SOURCE TRACKING AND MONITORING, PHASE II FINAL REPORT
}

\author{
T. A. Warren \\ R. M. Walker \\ D. E. Hill \\ I. G. Gross \\ C. M. Smith \\ R. K. Abercrombie
}

Date Published: January 2007

Prepared by

OAK RIDGE NATIONAL LABORATORY

Oak Ridge, Tennessee 37831-6283

managed by

UT-BATTELLE, LLC

for the

U.S. DEPARTMENT OF ENERGY

under contract DE-AC05-00OR22725 



\section{CONTENTS}

LIST OF FIGURES

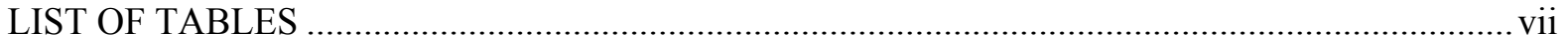

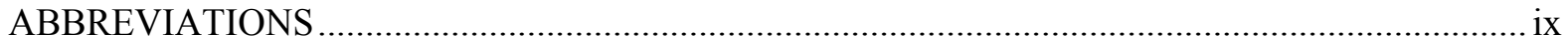

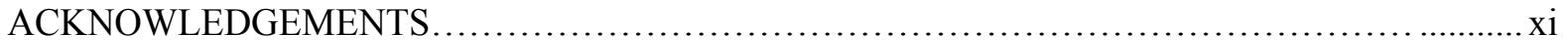

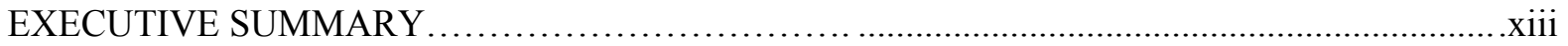

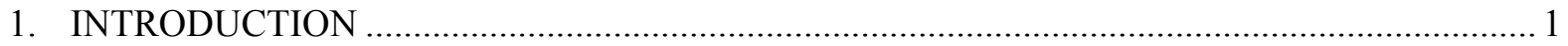

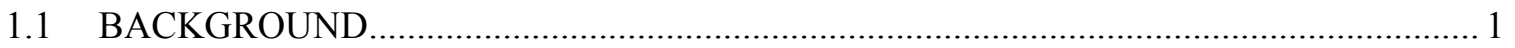

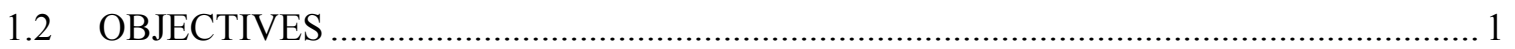

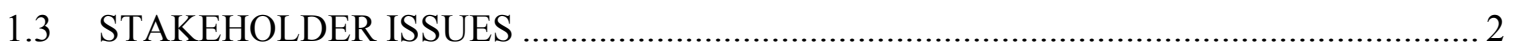

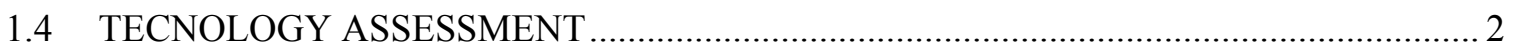

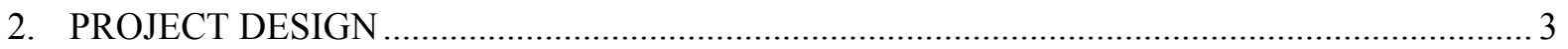

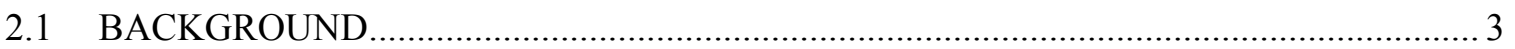

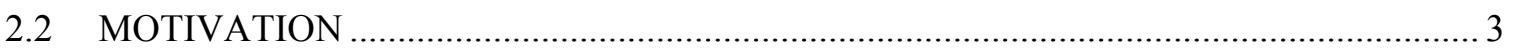

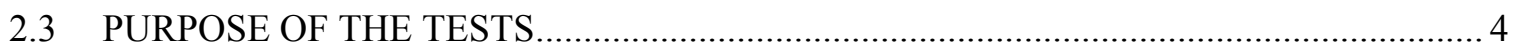

2.4 RADIO FREQUENCY INDENTIFICATION (RFID) .............................................. 4

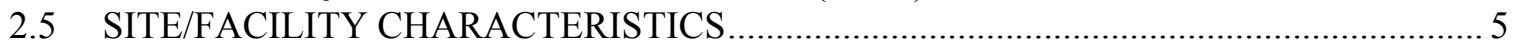

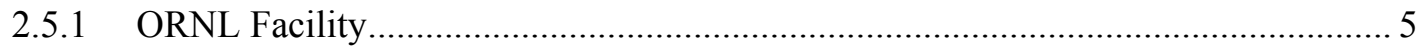

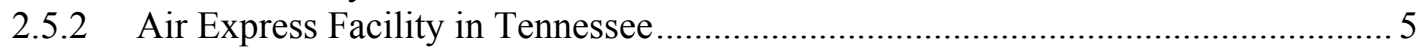

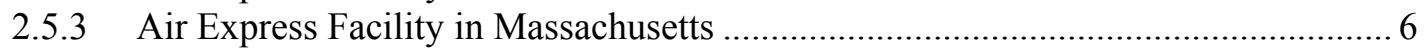

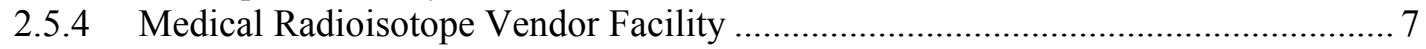

3. RADSTRAM RFID SYSTEM COMPONENTS .................................................................. 9

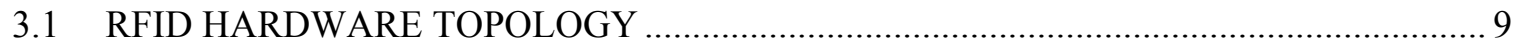

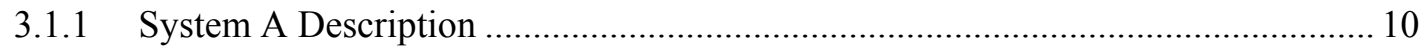

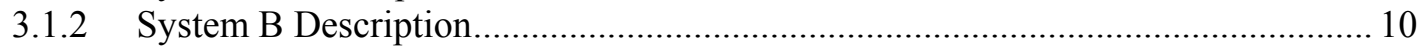

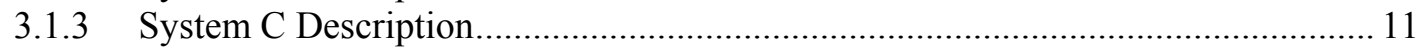

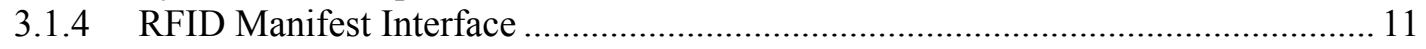

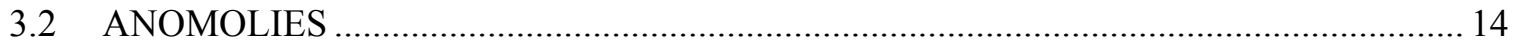

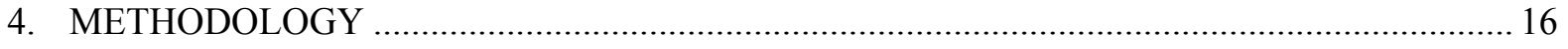

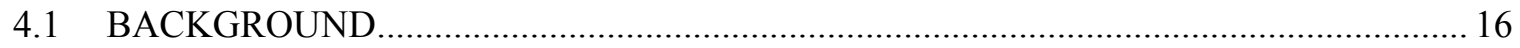

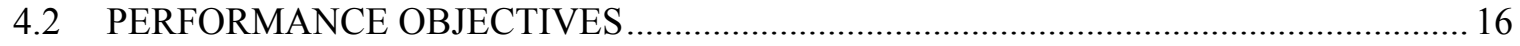

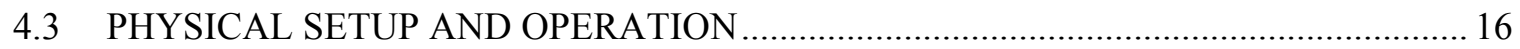

4.4 TEST PROCEDURES FOR THE MEDICAL RADIOISOTOPE SHIPMENTS................20

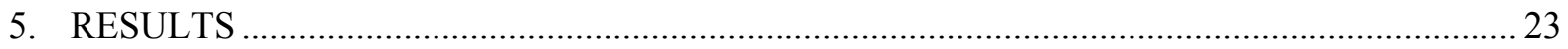

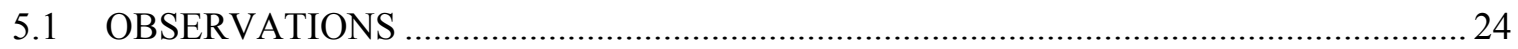

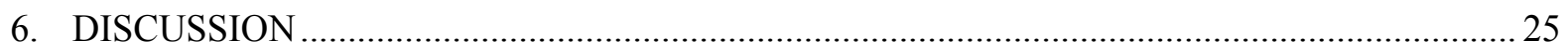

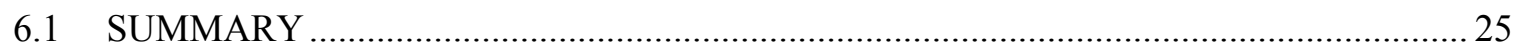

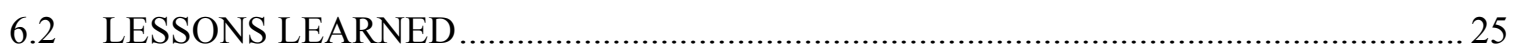

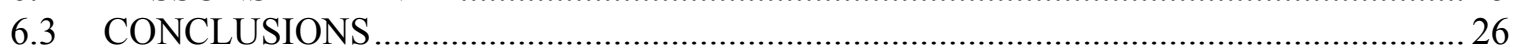

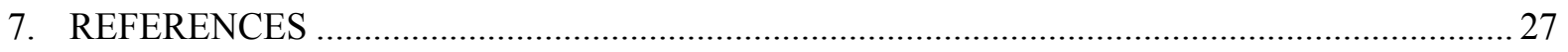

Appendix A: GENERAL RFID SYSTEM OVERVIEW .................................................... A-1 



\section{LIST OF FIGURES}

Figure $\quad$ Page

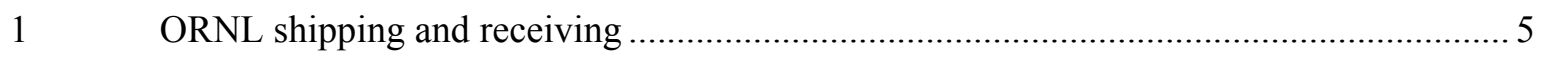

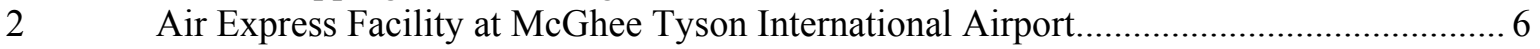

3 Air Express Facility at Logan International Airport ..................................................... 7

$4 \quad$ Medical Radioisotope vendor's shipping and receiving area ....................................... 8

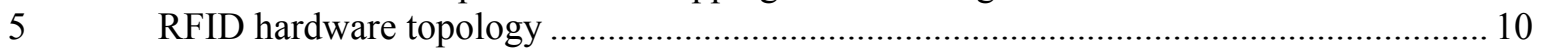

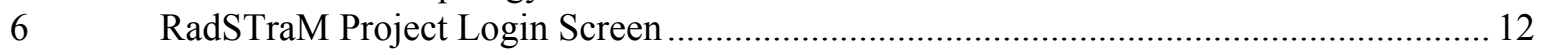

$7 \quad$ RadSTraM Viewer, Shipments Details Screen ...................................................... 13

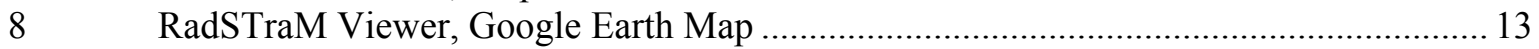

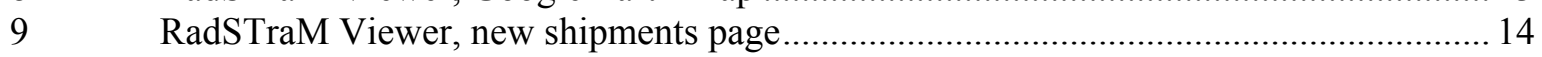

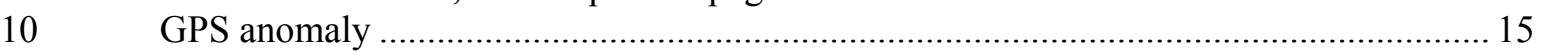

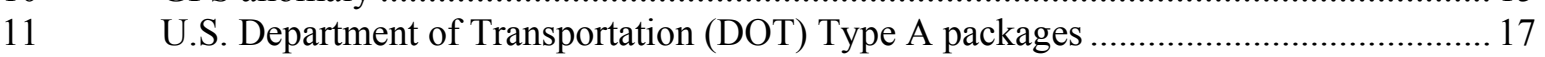

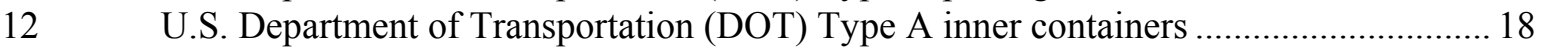

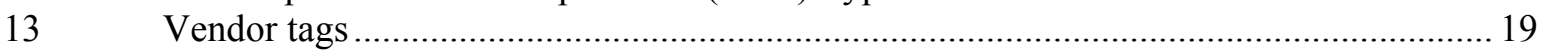

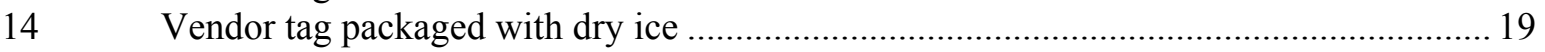

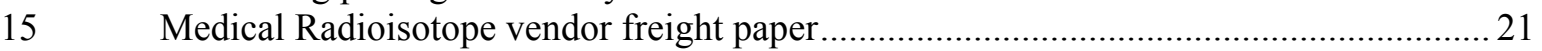

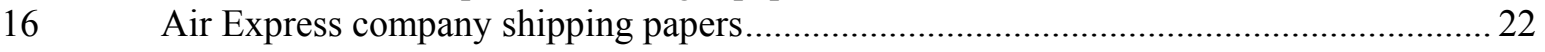





\section{LIST OF TABLES}

Table

Page

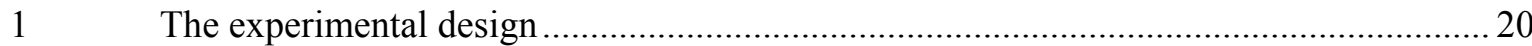

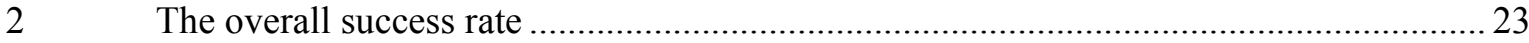

3 Ambient air vs. dry ice comparison of success rates for each system ...........................23

4 Ambient air vs. dry ice comparison of success rates for each system in the presence

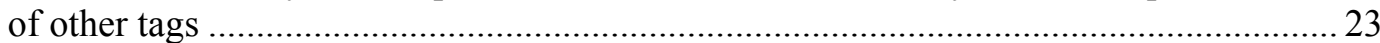

$5 \quad$ Comparison of each system's success rates for shipments packaged with P32

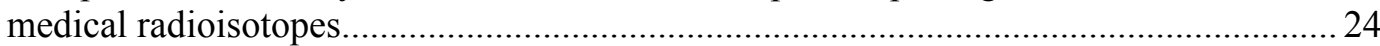

6

Implementation of Phase I lessons learned in Phase II of testing...

25 



\section{LIST OF ABBREVIATIONS}

$\begin{array}{ll}\text { AE } & \text { Air Express } \\ \text { API } & \text { Application Programming Interface } \\ \text { COTS } & \text { Commercial Off-the-Shelf } \\ \text { DHS } & \text { Department of Homeland Security } \\ \text { DOE } & \text { Department of Energy } \\ \text { DOT } & \text { Department of Transportation } \\ \text { EPA } & \text { Environmental Protection Agency } \\ \text { FRMAC } & \text { Federal Radiological Monitoring and Assessment Center } \\ \text { GC } & \text { Gateway Controller } \\ \text { GPS } & \text { Global Positioning System } \\ \text { IAEA } & \text { International Atomic Energy Agency } \\ \text { MR } & \text { Medical Radioisotope } \\ \text { NRC } & \text { Nuclear Regulatory Commission } \\ \text { ORAU } & \text { Oak Ridge Associated Universities } \\ \text { ORNL } & \text { Oak Ridge National Laboratory } \\ \text { P-32 } & \text { Phosphorus 32 } \\ \text { RadSTraM } & \text { Radiation Source Tracking and Monitoring } \\ \text { RFID } & \text { Radio Frequency Identification } \\ \text { RSI } & \text { Remote Sensor Interface } \\ \text { RTLS } & \text { Real-time Tracking and Locating System } \\ \text { STC } & \text { Strong-tight Containers } \\ \text { UWB } & \text { Ultra-Wide Band } \\ \text { WAN } & \text { Wide Area Network }\end{array}$





\section{ACKNOWLEDGMENTS}

The authors gratefully acknowledge Deborah Kopsick and the Office of Radiation and Indoor Air at the Environmental Protection Agency (EPA) for sponsoring the development of RadSTraM (Radiation Source Tracking and Monitoring). They also wish to thank the various participants at Oak Ridge National Laboratory (ORNL), the Department of Energy (DOE), PerkinElmer, DHL, Aeroscout, TeraHop (formerly SeekerNet), and WaveTrend. The mention of brand names in this report does not constitute endorsement by the U.S. Government. 


\section{EXECUTUVE SUMMARY}

One of the main components of the Environmental Protection Agency's (EPA) Clean Materials Program is to prevent the loss of radioactive materials through the use of tracking technologies. If a source is inadvertently lost or purposely abandoned or stolen, it is critical that the source be recovered before harm to the public or the environment occurs. Radio frequency identification (RFID) tagging on radioactive sources is a technology that can be operated in the active or passive mode, has a variety of frequencies available allowing for flexibility in use, is able to transmit detailed data and is discreet. The purpose of the joint DOE and EPA Radiological

Source Tracking and Monitoring (RadSTraM) project is to evaluate the viability, effectiveness and scalability of RFID technology under a variety of transportation scenarios.

The goal of the Phase II was to continue testing integrated RFID tag systems from various vendors for feasibility in tracking radioactive sealed sources which included the following performance objectives:

1. Validate the performance of RFID intelligent systems to monitor express air shipments of medical radioisotopes in the nationwide supply chain,

2. Quantify the reliability of these tracking systems with regards to probability of tag detection and operational reliability,

3. Determine if the implementation of these systems improves manpower effectiveness, and

4. Demonstrate that RFID tracking and monitoring of radioactive materials is ready for large scale deployment at the National level.

For purposes of analysis, the test scenario employed in this study utilized the real world commerce supply chain process for radioactive medical isotopes to validate the performance of intelligent RFID tags. Three different RFID systems were assessed from a shipping and packaging perspective, included varied environmental conditions, varied commodities on board vehicles, temporary staging in shipping terminals using various commodities and normal transportation handling. We tracked 32 air express (AE) shipments from a medical radioisotope (MR) production facility in Boston, MA to ORNL in Oak Ridge, TN. Each RFID system was individually tested in Type A modified packaging with differing quantities of Phosphorus-32 $(1,000 \mu \mathrm{ci}, 500 \mu \mathrm{ci}$ and $250 \mu \mathrm{ci})$ for 16 shipments per system. Three of these shipments per system contained dry ice (9 total). An additional 16 shipments were tested that contained one tag from each system using Type A packaging without Phosphorus- 32 . Twelve of these shipments contained dry ice. RFID interrogators for each system were installed at four waypoints along the 1,000 mile shipping route from source to designation via air and surface. Each package was expected to be detected by its corresponding interrogator(s) at each waypoint.

System A's overall probability of detection was 77 percent, System B's overall probability of detection was 20 percent and System C's overall probability was 75 percent. The presence of more than one RFID system in a shipment did not appear to have an effect on any of the three systems tested. However, no tests of significance could be performed because group sample sizes did not satisfy the standard binomial test-of-significance between independent samples.

The presence of dry ice appeared to have a deleterious effect on System C, but again sample sizes did not satisfy the standard binomial requirement for test of significant difference between independent proportions and conclusions cannot be drawn for these results. Phase II of the RadSTraM project verified that RFID tagging can be applied to the tracking and monitoring of medical radioisotope air express shipments. This study demonstrated that active RFID tagging systems can be feasibly integrated and scaled into the nation-wide supply chain to track and monitor medical radioisotopes. 


\section{INTRODUCTION}

This report focuses on the technical information gained from the Radiological Source Tracking and Monitoring (RadSTraM) Phase II investigation and its implications. The intent of the RadSTraM project was to determine the feasibility of tracking radioactive materials in commerce, particularly International Atomic Energy Agency (IAEA) Category 3 and 4 materials. Specifically, Phase II of the project addressed tracking radiological medical isotopes in commerce. These categories of materials are susceptible to loss or theft but the problem is not being addressed by other agencies.

\subsection{BACKGROUND}

One of the main components of the Environmental Protection Agency's (EPA) Clean Materials Program is to prevent the loss of radioactive materials through the use of tracking technologies. If a source is inadvertently lost or purposely abandoned or stolen, it is critical that the source be recovered before harm to the public or the environment occurs. Radio frequency identification (RFID) tagging on radioactive sources is a technology that can be operated in the active or passive mode, has a variety of frequencies available allowing for flexibility in use, is able to transmit detailed data and is discreet. The purpose of the joint DOE and EPA RadSTraM project is to evaluate the viability, effectiveness and scalability of RFID technology under a variety of transportation scenarios.

Phase I of the study served as a critical component for addressing procedures and protocols needed to establish an operational system. During the first phase, RFID was used to track radiological commodities under typical "in commerce" shipping conditions. The project tracked a series of shipments between Oak Ridge National Laboratory (ORNL) and Oak Ridge Associated Universities (ORAU) utilizing commercial Less-than-Truckload service, commercial truckload service and ORAU private fleet. The testing included single and multiple shipments under different loading and shielding scenarios. The scenarios included in transit as well as overnight storage, and they were tracked using bulk radiological monitors at the I-40 Watt Road weigh station. The testing coupled data from two RFID technologies with data collected from radiation portal monitors. This set of tests verified that active RFID tagging can be applied to the tracking of interstate shipments of radioactive material. Furthermore, it was demonstrated that RFID systems are robust and mature enough to be scaled into a nation-wide system with the caveat that there is some central database or network that can present the data to a variety of users (1).

Phase II implemented the procedures, protocols and lessons learned during Phase I into a real-world environment to test proof-of-concept with a range of tags for large-scale deployment. RFID systems were used to track, locate and identify express air and truck shipments of medical radioisotopes shipped by a commercial air express (AE) service between a medical radioisotope (MR) production facility in Massachusetts and ORNL in Tennessee. An RFID manifest system consisting of a standalone database and web client was developed to manage data from the tags from several different vendors. The RadSTraM project used operational procedures set by the Department of Energy (DOE) Isotopes Group for medical and industrial supply chain shipments of radioactive materials. This initiative was unique because it implemented lessons learned from the previous test phase to evaluate instrument technology in a real world deployment.

\subsection{OBJECTIVES}

The goal of this project was to continue testing integrated RFID tag systems from various vendors for feasibility in tracking radioactive sealed sources. This technology was chosen for a number of reasons, including: 
1. the cost of RFID tag systems have become affordable,

2. the technology has flexibility in frequencies used, allowing detection a varying distances from the reading device,

3. tags may be passive or active and may be combined with other sensors and technologies, such as Global Positioning Satellite tracking,

4. RFID testing can be combined with ongoing or planned in-commerce projects at ORNL's test-bed at the I-40 Weigh station in Knox County, Tennessee.

\subsection{STAKEHOLDER ISSUES}

The stakeholders identified in this demonstration were the Department of Energy (DOE), Oak Ridge National Laboratory (ORNL), the Environment Protection Agency (EPA), the manufacturers and distributors of radioactive medical isotopes, commercial air express (AE) companies, state and local governments, and the general public. All of the stakeholders desire the ability to track radioactive material in transit. For ORNL, this desire was based on inquiries by the Nuclear Regulatory Commission (NRC) requiring ORNL to provide location information of their radioactive material shipments. It is anticipated that the manufactures, distributors and AE companies that transport radioactive material will desire this same information to reduce risk and potentially reduce insurance premiums. The general public wants safe roadways as well as the stringent regulation of radioactive material shipments.

\subsection{TECHNOLOGY ASSESSMENT}

The instruments and technologies used for the RadSTraM study were chosen because they utilize the latest off-the-shelf technology. As such, the components used were experimental in nature with distinct advantages and limitations. These are outlined in detail in Section 3 of the document. 


\section{PROJECT DESIGN}

The experimental design for the RadSTraM study combines off-the-shelf technology into an intelligent system that meets criteria established for successfully implementing and testing the project requirements. Section 3 covers the demonstration plan as it relates to the real-world facilities used for the study.

\subsection{BACKGROUND}

Radiation has existed everywhere in the environment, rocks soil, water and plants, since the Earth's formation. The mining and processing of naturally occurring radioactive materials for use in medicine, power generation, consumer products, and industry inevitably generate emissions and waste. Recognizing the potential hazards of these activities, Congress designated the Environmental Protection Agency as the primary federal agency charged with protecting people and the environment from harmful and avoidable exposure to radiation. Essentially, the number of unwanted radioactive sources in the United States is not known, as no records of this type are kept, but the IAEA estimates 18-38 million packages of radioactive materials are shipped each year worldwide (2). The NRC receives approximately 300 reports of lost, stolen or abandoned radioactive sources a year. The Director General of the IAEA reported that orphan sources are a widespread problem with 34 of 49 countries responding to a U.S Government Accountability Office survey indicating that orphan sources pose problem in their country. These respondents reported 612 sources lost or stolen since 1995 with 254 unrecovered (3). The U.S. Department of Energy estimates it will recover over 14,000 greater-than-Class-C sealed sources by 2010 (2). Understanding the extent and nature of a radiological emergency is essential for limiting its adverse effects. In an emergency, the DOE and EPA establish a Federal Radiological Monitoring and Assessment Center (FRMAC) to define and monitor the radiological impact.

Specifically, EPA is the designated Lead Federal Agency in a multi-agency response to releases from accidents in commerce of unknown radiological materials, not licensed, owned or operated by a Federal agency or an Agreement State. In this capacity EPA coordinates with the DOE, since DOE has the lead responsibility for coordinating the FRMAC, during the early phase of a radiological emergency. The earliest identification of radiological (in commerce) sources is paramount in this process.

Oak Ridge National Laboratory (ORNL) is providing support to the EPA, Department of Homeland security (DHS), and DOE in their goal of proving technologies associated with the detection and clearance of radiological materials in-transit. ORNL is also providing support to the Tennessee Department of Safety in their goal of proving technologies associated with the enforcement of commercial vehicle state and federal laws associated with radiological materials and their transport. This is an innovative initiative includes all facets of real world deployment such as instrument technology evaluation, secure communications, operational protocols, information technologies, cyber security, database development and technical reachback. The results from this study will serve as a critical component for addressing procedures and protocols needed to establish an operational system.

\subsection{MOTIVATION}

Highly radioactive sources are used in everyday life to treat cancer patients, as irradiators to preserve food, in industrial radiography to check for welding errors in pipelines and buildings, for thermoelectric generation of electricity in remote locations, and for a variety of other purposes. There are reportedly some ten thousand radiotherapy cancer treatment units worldwide, with many more radioactive sources used throughout industry. Radiological sources are essential to our societies, and there is not practical option to secure and control every item, everywhere. 
There is not accurate figure on how many radioactive sources exist throughout the world. Some of the isotopes of most concern include Cobalt 60, Strontium 90, Cesium 137, and Iridium 192. A huge number of applications of these materials make them inherently difficult to track and control. Many of these sources are lost, stolen, or simply abandoned when no longer required. In the United States, for example, an average of about 300 sources of radioactive material are reported lost or stolen each year (2). Such "orphaned" radioactive sources give cause for immense concern and is most in countries where civil authority and regulatory oversight are weak. Orphan sources are found worldwide. In early 2002, for example, two canisters containing highly radioactive Strontium 90 were discovered in the former Soviet republic of Georgia. The three Georgian woodsmen who came upon them were severely burned by radiation. The United States, the IAEA, and the Georgian government subsequently worked together to secure these field radioisotope thermoelectric generators, many of which exist in uncontrolled settings). Furthermore, there exist significant quantities of Cesium 137 that has been used to preserve harvested grain in some countries and become orphaned, for example. $(3,4,5,6)$

\subsection{PURPOSE OF THE TESTS}

The first step in the design and implementation of an RFID intelligent tag system into the supply chain process for radioactive materials is for a validation of this technology to be completed to assess how to best apply it to the in-commerce process. To this end, the RadSTraM Controlled Shipment Test Phase II was conducted to assess the technology in a real-world environment simulated after the DOE Isotopes shipping program at ORNL. This stage of the test plan addresses the nationwide supply chain using a major radioisotope supplier and shipper. Collaborations with the state/federal government agencies and the private sector will prove invaluable as RFID technologies are studies. It is envisioned that RFID technology will serve the primary need of the EPA to reduce the number of orphan sources and identify radioactive materials throughout their life cycle in the supply chain. Additionally, it is hoped that RFID will provide the capability to pre-clear vehicles that might set of radiation detection sensors to avoid further inspection of the vehicle.

\subsection{RADIO FREQUENCY IDENTIFICATION (RFID)}

To mitigate the risk associated with the conditions outlined above, the application of emerging technologies and commercial off-the-shelf (COTS) products should be demonstrated and tested. One such technology, radio frequency identification (RFID) intelligent tags, might provide a solution. RFID is a technology that has been used for several years to track consumer products, railroad cars, domesticated animals and even people. RFID tags are intelligent labels that can talk to an interrogator or reader to indicate that the tag is within a predetermined range. RFID technology uses radio waves to transmit a serial number or other data that can identify a person or object.

The basic concept: the RFID transponder or RFID tag is typically a silicon microchip with unique identification information attached to an antenna. The antenna enables the chip to transmit the information to reader. The reader converts the radio waves from the RFID tag into digital information that can then be passed on to computers that can interpret the information.

A ubiquitous network of RFID interrogators can track tags attached to hazardous and radiological cargo through every phase of its transportation route. The readers that communicate directly with these smart labels and the Internet will serve as the communications network. The location of the RFID tag can be tracked by computer, personal digital assistant or cell phone. This technology application is especially relevant in light of the fact that many radiological monitoring and detection systems are in various stages of deployment throughout the world at transportation chokepoints and inter-modal facilities. 


\subsection{SITE/FACILITY CHARACTERISTICS}

\subsubsection{ORNL Facility}

ORNL's shipping and receiving department is a 15,000 square feet facility with a 30 'x 30 ' room where radiological shipments are required to be stored. All inbound and outbound shipments are stored here until ready to be moved on. The RFID interrogators were installed just outside the room above the door, see Figure 1.

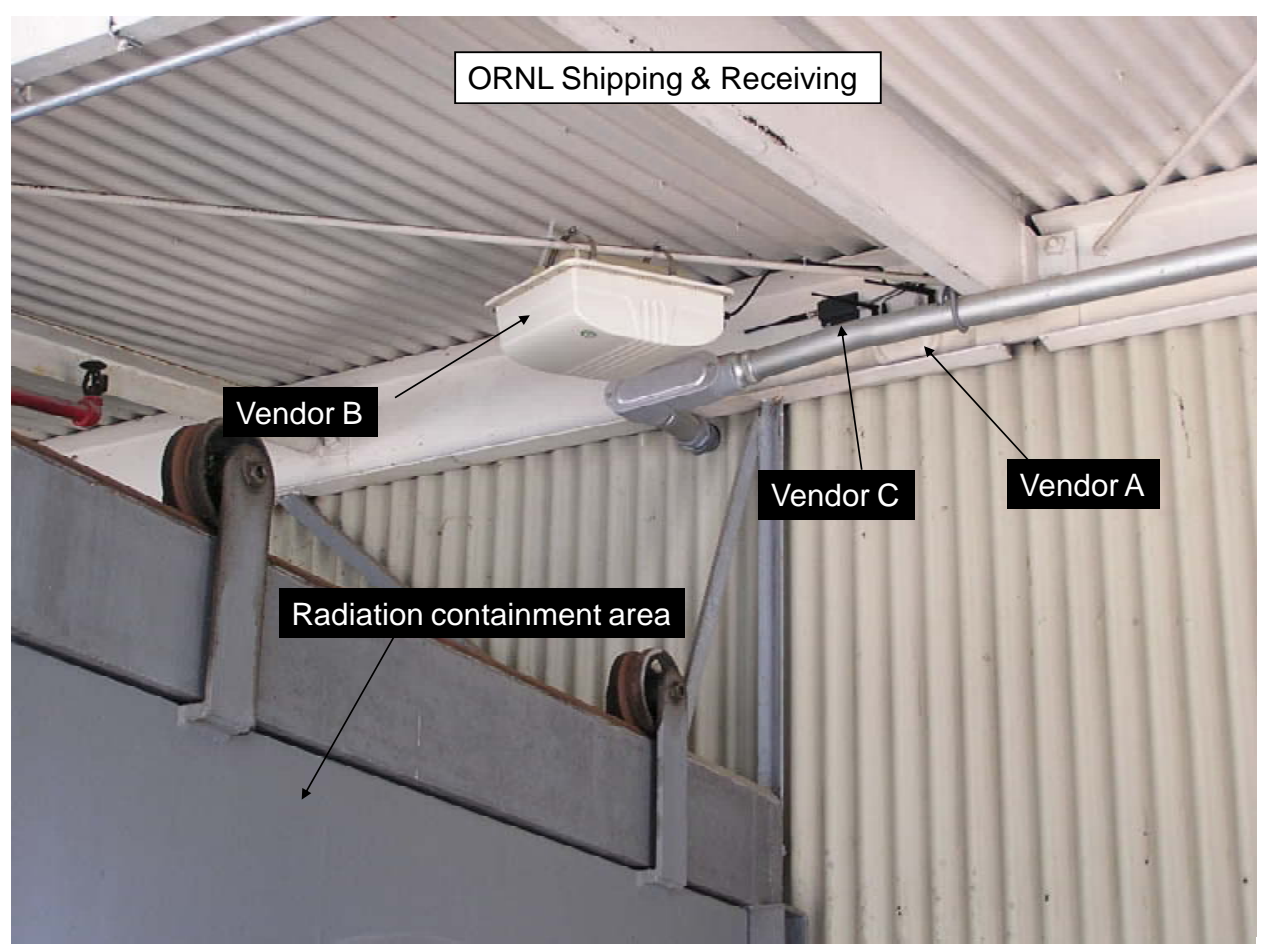

Figure 1. ORNL shipping and receiving area.

\subsubsection{Air Express Facility in Tennessee}

The AE facility at the McGhee-Tyson Airport is located in Alcoa, Tennessee. The 15,000 square foot distribution warehouse is located inside the airport perimeter. There are several loading and unloading doors. The interrogators were located near the inbound door where most AE planes are unloaded, see Figure 2. This provided the optimal condition to see the tagged shipments as they were brought into the building. However, this location made it possible outgoing shipments would be difficult for the readers to detect. The interrogators were set on a high shelf just inside the inbound door. 


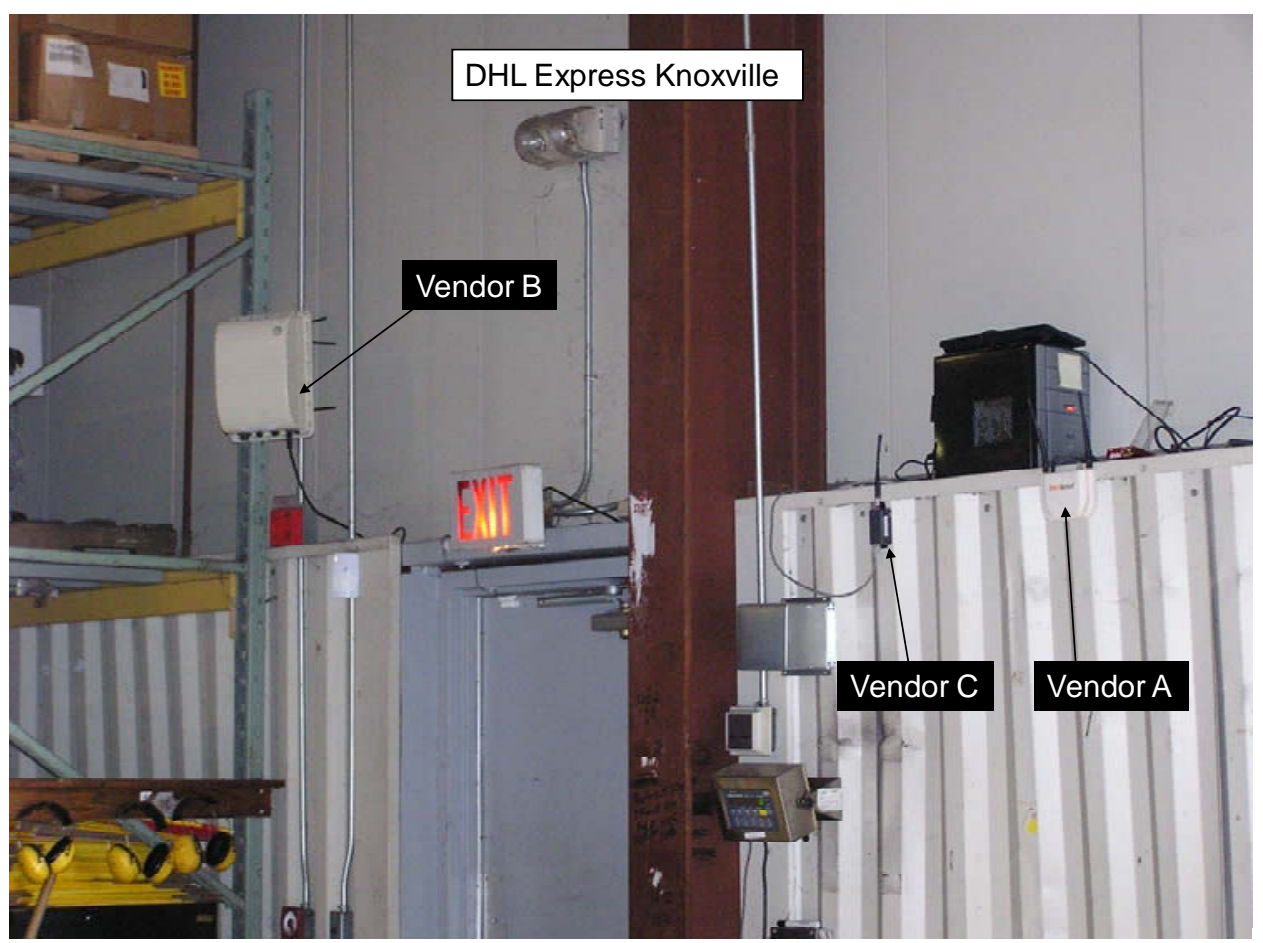

Figure 2. Air Express Facility at McGhee-Tyson International Airport.

\subsubsection{Air Express Facility in Massachusetts}

The AE facility at Logan International Airport in Boston, Massachusetts is a 60,000 square foot warehouse. The loading dock has several unloading bays but only two loading bays that are near the electrical control room for the entire warehouse. All radiological shipments coming from medical radioisotope vendor are packed for shipment within 30 feet of this room. This was the best location that we found to install the readers as they were up 9 feet above the floor and out of the way of any shipping lanes, see Figure 3. 


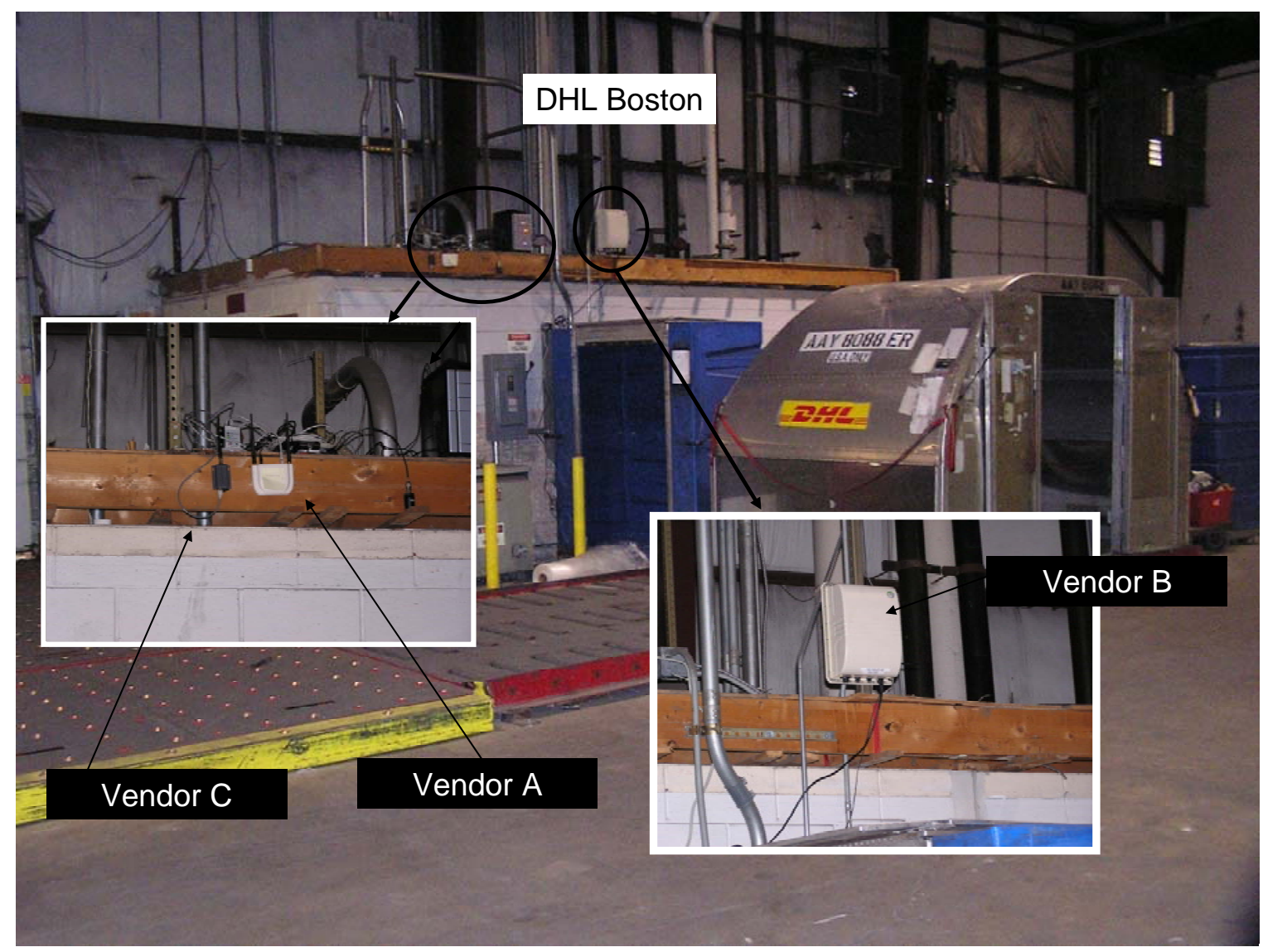

Figure 3. Air Express Facility at Logan International Airport.

\subsubsection{Medical Radioisotope Vendor Facility}

The medical radioisotope vendor has a 3,600 square foot shipping department with three loading and unloading doors. Each medical radioisotope shipment is packed in a box and sent down a conveyor to the shipping department. From there shipping stickers are placed on the boxes and the boxes are placed on pallets that are picked up by the AE courier. The conveyor passes within 30 feet the interrogators and the pallets are stored just on the other side of the partition. The interrogators were set in this location as space was limited and it provided the best height to not interfere with normal business activity, see Figure 4. 


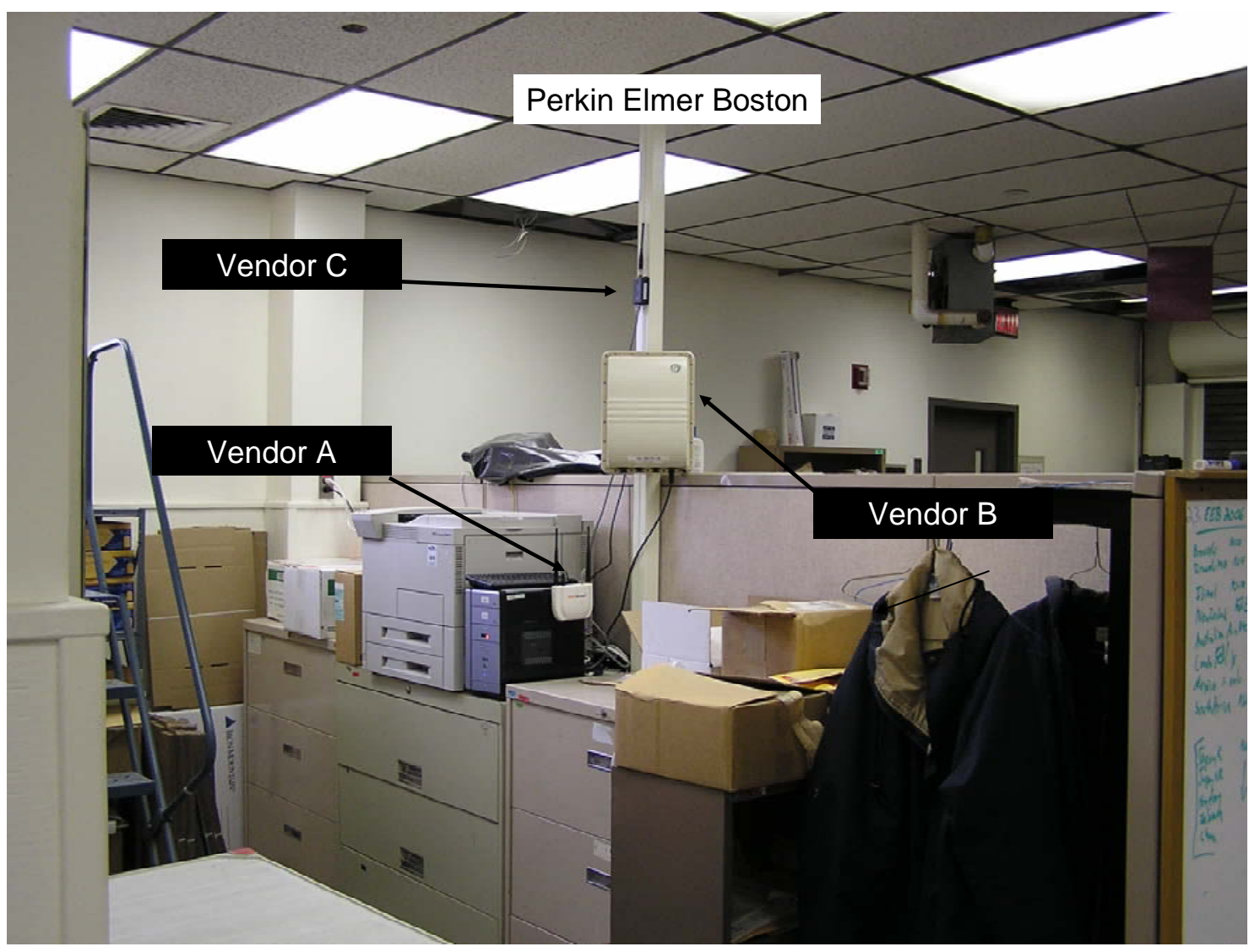

Figure 4. Medical Radioisotope vendor's shipping and receiving area. 


\section{RADSTRAM RFID SYSTEM COMPONENTS}

The technologies tested in this study were chosen from a pool of qualified RFID vendors who responded to an open call for participants. Vendors invited to participate in the demonstration were required to have prerequisite background knowledge, experience and capability to successfully meet or exceed the requirements of the test. Furthermore, vendors were required to provide product line samples and support at no charge to the government. Initially, five vendors were chosen to participate in the RadSTraM project. Two vendors dropped out of the project because problems in the production of their product prevented them from meeting the project schedule. The three vendor technologies used in the test will be referred to as System A, System B and System C in this report.

Participants in the project were required to provide a technological solution that would monitor medical radioisotope shipments while in transit using passive, active or hybrid RFID tags or a combination thereof. Furthermore, the following requirements had to be satisfied:

1. RFID tags with omni-directional read distances up to 50 feet at a frequency available worldwide.

2. The tag readers must recognize the tags when transported in metal trailers traveling at speeds up to $30 \mathrm{mph}$.

3. The readers must recognize tags in the presence of other tags.

4. Readers needed to read tags at four locations: one at the medical isotope supplier in Boston, Massachusetts, one at the air express terminal at Logan International Airport in Boston, Mass, one at the air express terminal at McGhee Tyson Airport in Knoxville, Tennessee, and one at ORNL in Oak Ridge, Tennessee.

5. Tags had to perform in any and all weather conditions and normal shipping and handling conditions.

6. The systems needed a lifespan of seven years without maintenance.

7. The systems needed an application programming interface (API) providing programmatic access to tag data including, at a minimum, the tag ID and a timestamp of when it is seen by a reader.

\subsection{RFID HARDWARE TOPOLOGY}

The RFID hardware topology consists of tag interrogators, cellular and Internet communications, and a database for storing and tracking the data (Figure 5). The database ran a table in Oracle with a web-based front-end. 


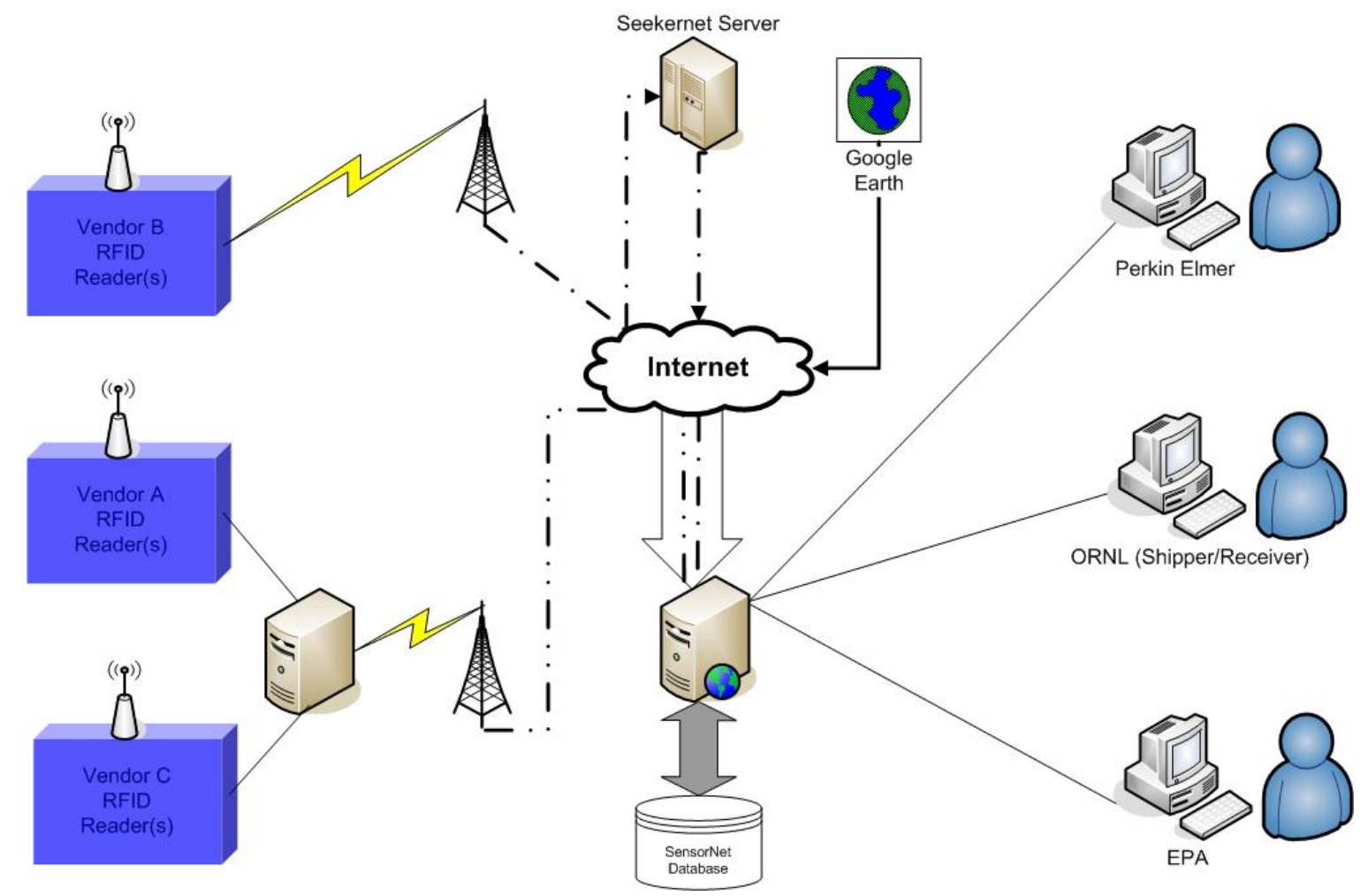

Figure 5. RFID hardware topology.

\subsubsection{System A Description}

System A uses standard $\mathrm{WiFi}^{\mathrm{TM}}$ wireless networks or any 802.11 -enabled wireless device to locate and track assets. The technology tested in this project used Cisco wireless access points to act as RFID readers and other $\mathrm{Wi}^{-\mathrm{Fi}^{\mathrm{TM}}}$ devices, without interrupting their normal operations. This feature turns a wireless network into a complete, full-featured real-time tracking and locating system (RTLS). Little or no additional hardware or network cabling is required to realize this RTLS. A single access point picks up active RFID tag messages in its coverage area. System A's software provides management of complete RTLS system and an application for user-defined alerting, notification and asset management. A platform is also provided for linking to existing data systems.

System A's interrogators were not able to connect directly to a cellular modem. A computer system designed to pass the data from the readers to a cellular modem was set up. Each reader had its own software interface running on the computer. Each computer reported its "hard coded" global positioning system (GPS) location to the database with each tag's relevant information (i.e., identification number, vendor tag type, event type, data source, date and timestamp).

System A's tags are programmable to send $802.11 \mathrm{~b}$-compatible messages at predefined intervals. The tags include clear channel assessment that prevents messages from being sent when $\mathrm{Wi}^{-\mathrm{Fi}^{\mathrm{TM}}}{ }^{\mathrm{T}}$ data traffic is present.

\subsubsection{System B Description}

System B uses a remote sensor interface (RSI) to integrate a Bluetooth/Ultra-Wide band (UWB) radio and multiple sensors in a compact form factor. The RSI relays information between other RSIs and/or the 
Gateway Controller (GC) and control the sensor/senor interface. GCs act as mobile access points or readers and provide the Wide Area Network connection (WAN) between RSIs and the management platform. The GC supports Bluetooth, $\mathrm{WiFi}^{\mathrm{TM}}$, mobile phone, satellite and Ethernet communications. The management platform provides status view and control of GCs and RSIs. The management platform also provides the Application Program Interface (APIs) to mainstream applications and to popular databases such as Oracle and MS-SQL. The platform is able to dynamically configure the RSI network according to a "Class-Based" networking capability that "wakes up" radios only within the desired class network, thereby reducing power consumption and radio frequency noise.

The System B's interrogator consisted of a cellular modem, GPS, and RFID reader encased in a weatherproof enclosure. This interrogator is a standalone unit that required no additional hardware to link to the Internet. The data from the interrogator was sent to a server at System B's office in Atlanta, Ga. using a proprietary data format. The server then converted the data into a web service then injected the data with either POST or GET to forward the information to the ORNL SensorNet server. From there the database was populated with the tag identification number, GPS location (longitude, latitude), vendor identification tag type, event type, data source, details information and a date and timestamp. The details information for this tag type gave additional status information of the tag. Details like "Arrival PE_BOS", or "In motion DHL_BOS".

System B's tags have an accelerator sensor to activate the tag to send a signal. The tag will only send data while in motion. The purpose of this is to save battery life by not attempting to pass data while sitting still or while in storage. The status "arrival" indicates that the tags have shown up for the first time. "In motion" indicated that the tag is being moved in range of the reader.

\subsubsection{System C Description}

System C utilizes the $433 \mathrm{MHz}$ spectrum to detect and decode signals from its family of tags. Interpreted data is converted into electrical information that is passed down to a network of readers. Readers can be used in stand-alone mode or in a multi-drop asynchronous network where the "Node ID" is automatically assigned. Sensitivity adjustment and reader addressing can be done remotely via PC software application. Dynamic reader programming (configuration) is available via PC software application. The RFID tags signal at a pre-set time-interval for the duration of its life.

As with System A, System C's interrogators were unable to connect directly to a cellular modem. The computer system described above for System A was also set up for System C.

System C's tags transmit an RF signal at a preset time interval. Settings such as site identification, tag identification, tag age and transmission repetition interval are programmable. A collision avoidance algorithm is used to dispose the transmission around the mean repetition interval.

\subsubsection{RFID Manifest Interface}

A web-based RFID manifest system was developed at ORNL to manage the test data in real time. The RFID manifest system is a standalone database and web client developed as a proof of concept exercise for the vendors participating in the RadSTraM project. Actual implementation of the RFID tracking database in the national supply would be as an add-on module to manifest software systems that shippers currently use. Each shipper may have their own manifest database server that could securely manage the shipping company's manifest. This provides each shipper with the ability to manage their own tags while protecting their information from competing shippers. 
Screen shots of ORNL's manifest system are displayed in Figure 6- Figure 11. Figure 6 displays the RadSTraM Project Login screen. The RadSTraM manifest viewer provides a minimum layer of security through this page.

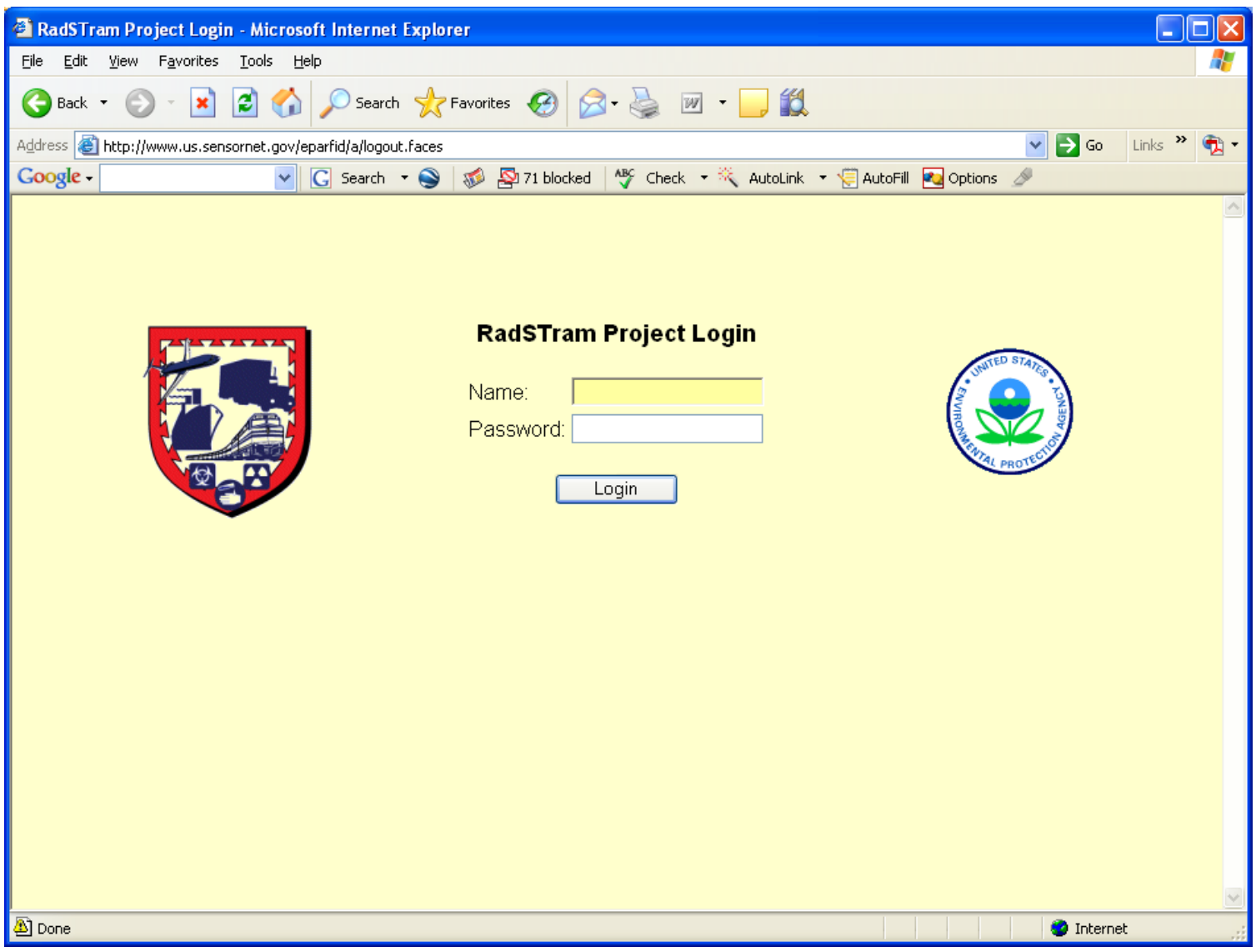

Figure 6. RadSTraM Project Login Screen.

Figure 7 displays the Shipments page of the viewer. This is the default page that the user sees upon logging in. On the left side of the screen, under the EPA logo is a menu with four buttons. This menu is visible on each page of the viewer. The default setting is "Shipment List". This page shows all shipments in the database. The next button, "New Shipments", allows the user to create a new RFID manifest. Under the "New Shipment" button on the Shipments page is the "Read Me" button. This is text help and information page. The fourth button on the Shipments page is "Log Out". When the user logs off the web page, the viewer returns to the RadSTraM Project Login screen. 


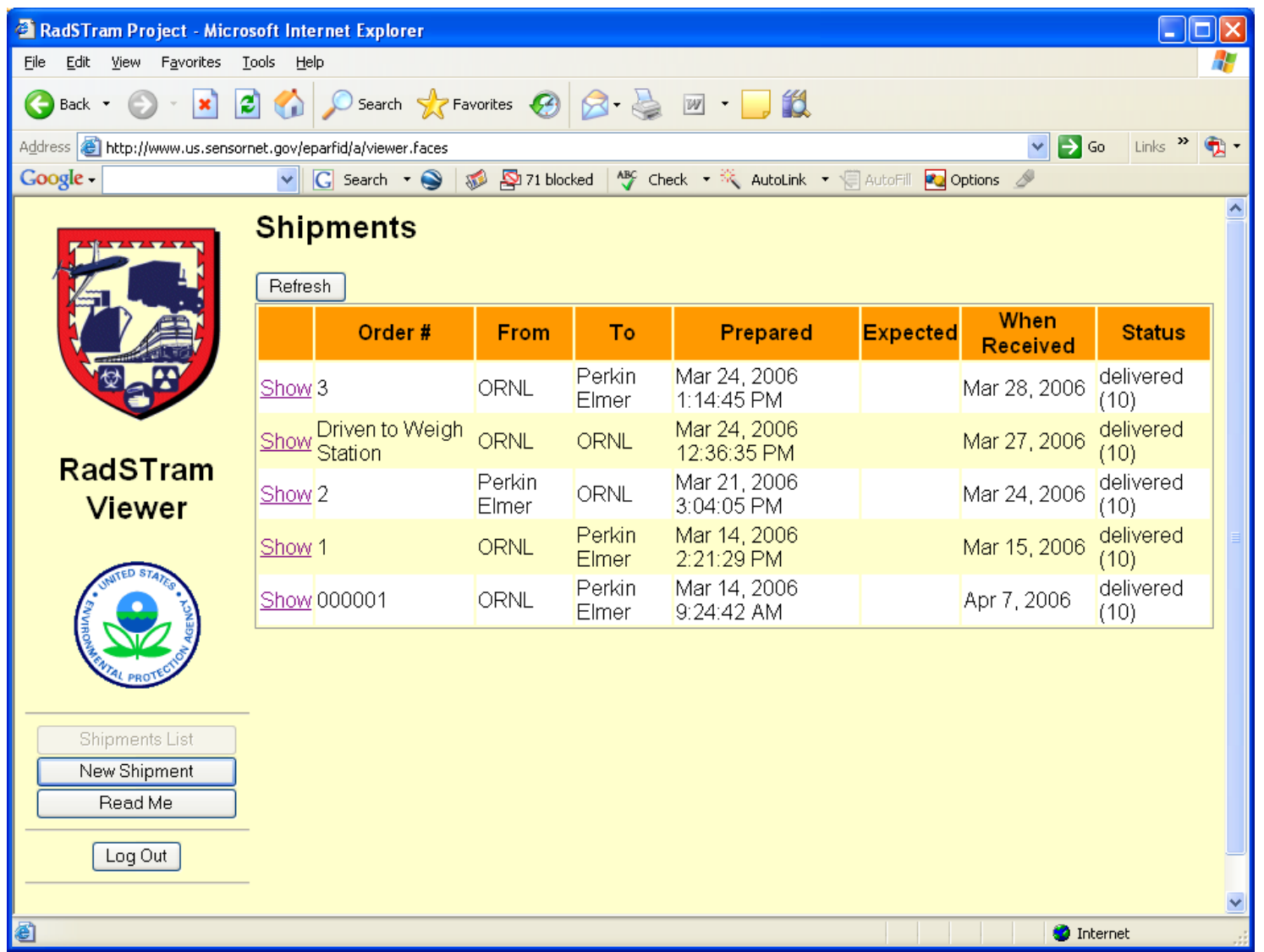

Figure 7. RadSTraM Viewer, Shipments Details Screen.

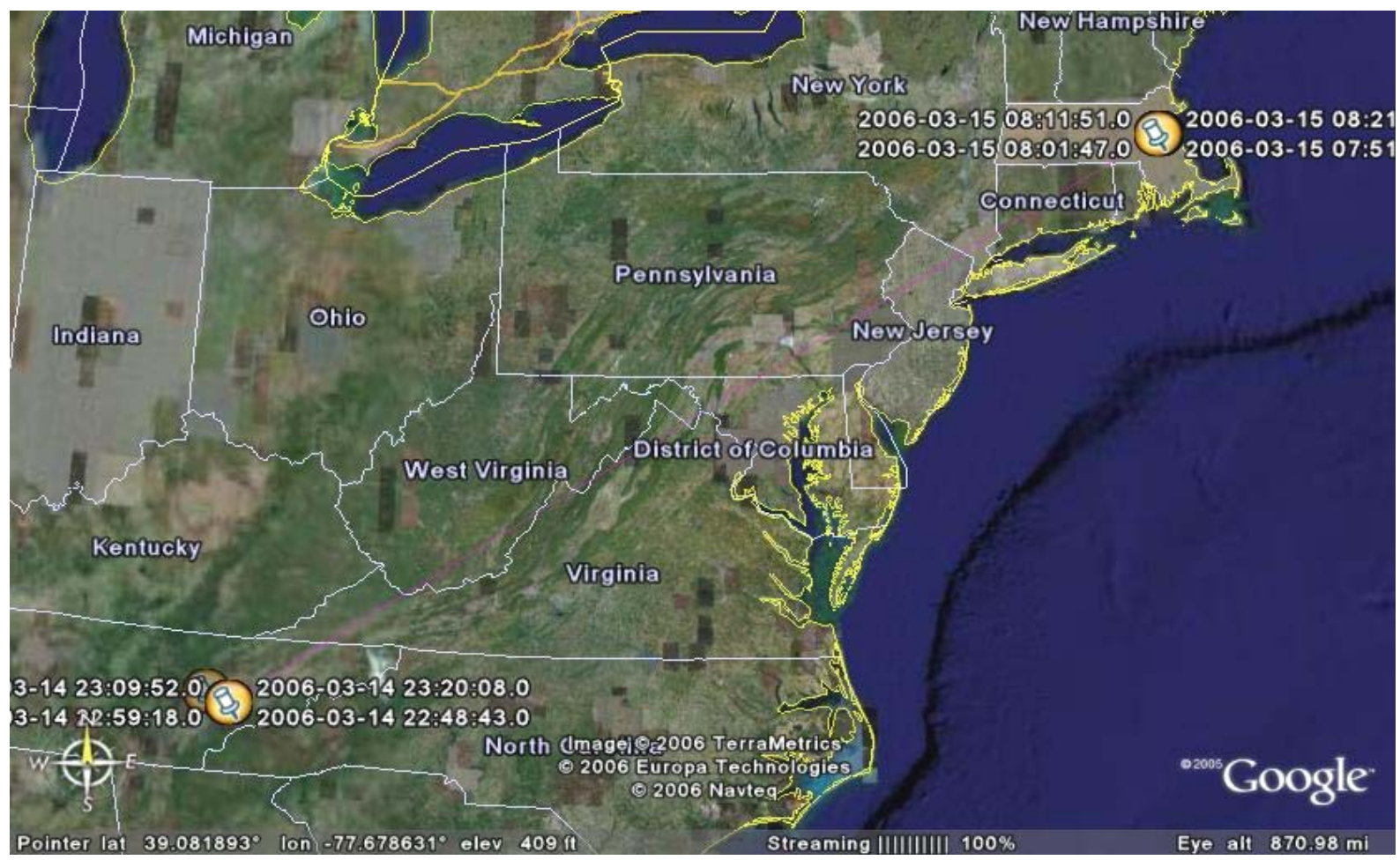

Figure 8. RadSTraM Viewer, Google Earth Map. 
Figure 10 displays the New Shipment page. On this page, the user creates a new RFID manifest record. The user selects the RFID tag(s) associated with a shipment along and provides the necessary shipping information. This information includes who the shipment is from, who it is being shipped to, the shipment number, the shipping method, the package tracking number, the expected time of arrival and any information from the manifest that the shippers wants to record. The "From", "To", "Shipping Method" and "Expected Arrival" field use pull down menus and the choices are not user modifiable. The "Shipment \#", "Package Tracking \#" and the "Manifest" fields are editable as this information is always unique. The information provided on this page populates the database.

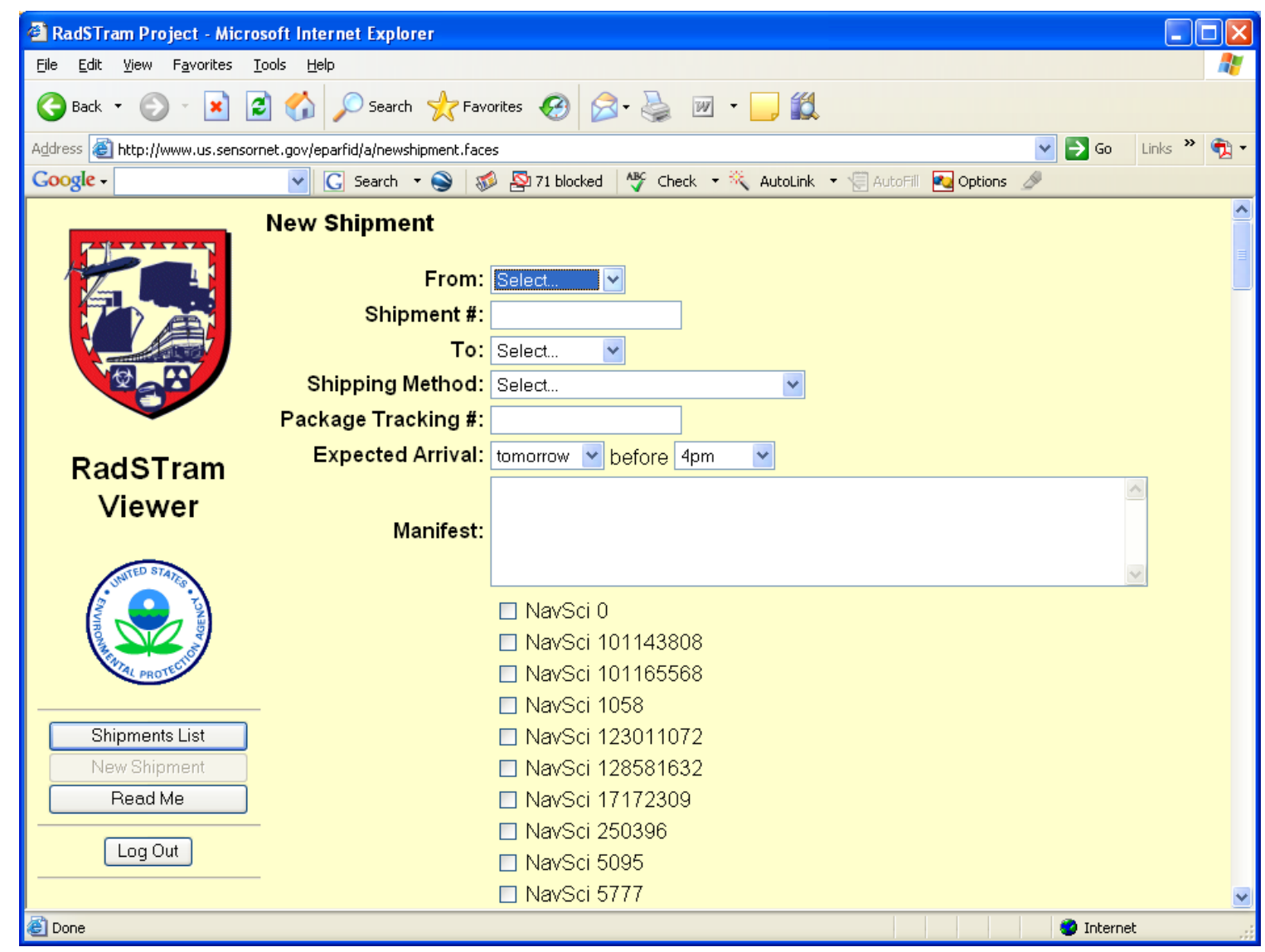

Figure 9. RadSTraM Viewer, new shipments page.

\subsection{ANOMALIES}

System B's RFID readers have built-in Global Positioning Systems (GPS). The tags from the other RFID vendors were located using ORNL's GPS. These systems lose their signal from time to time. Lost signals result in latitude/longitude readings of 0.0/0.0 and cause the tag locations on the Google Earth map to be displayed as being in the middle of the Atlantic Ocean. Additionally, GPS signal strength was decreased by the indoor location of ORNL's GPS antennas and the position of the satellites at different times of the day changed the availability of the signal. These types of errors are typical of GPS technology but the errors tend to be relatively small. As demonstrated in Figure 11, the inaccuracy of the GPS location is off by approximately 50 meters. This is typically not problematic unless competing shippers or receivers are within a 100 meter diameter of one another. 


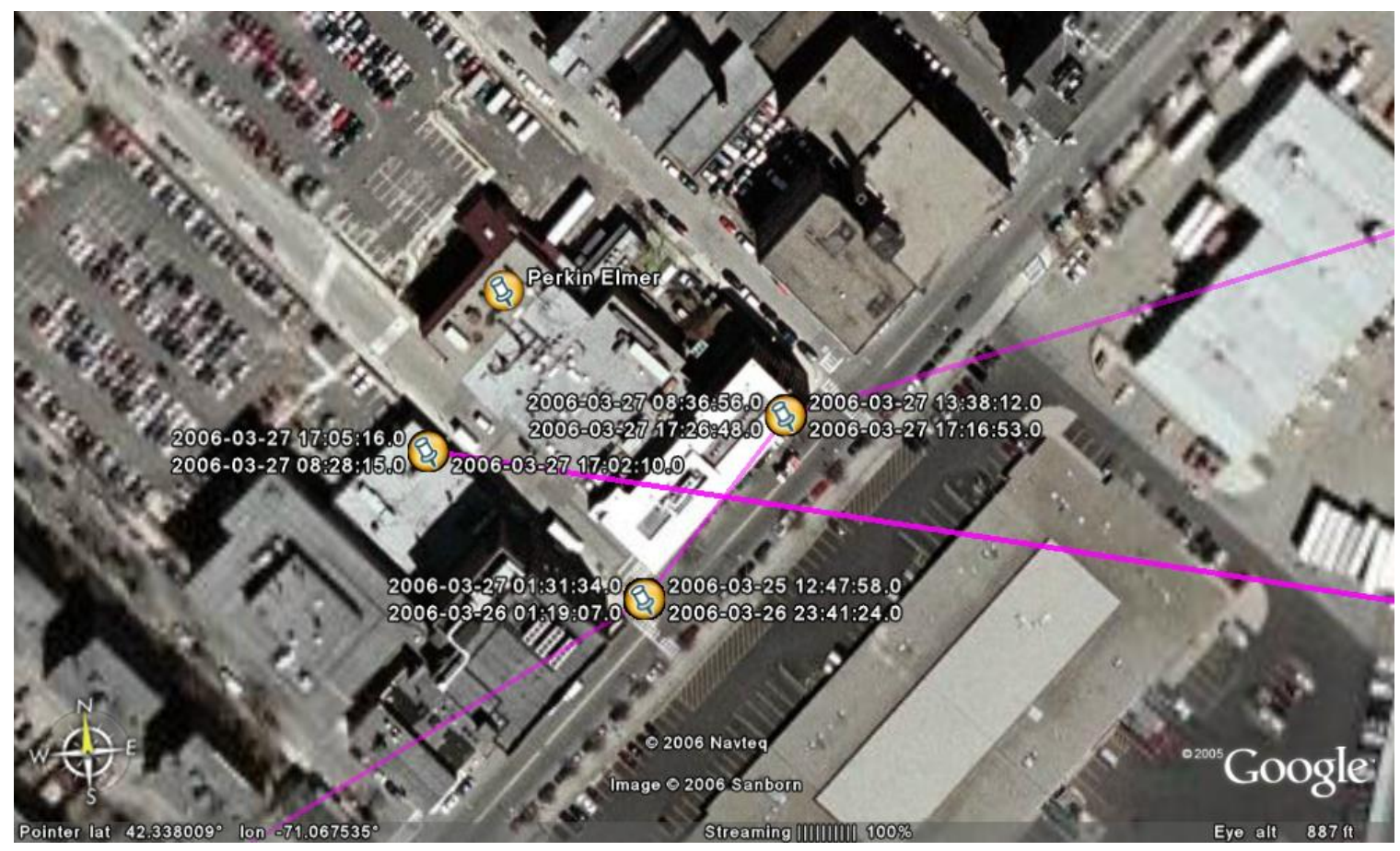

Figure 10. GPS anomaly. 


\section{METHODOLOGY}

In this section the RadSTraM shipping constraints are discussed in the context of testing the feasibility of using an RFID system to effectively reduce orphaned sources.

\subsection{BACKGROUND}

Questions of concern include: What are the most effective package tag/label and reader placement locations (options, tolerances)? What is the effective read rate and range? How well do these constraints fit with the typical shipping process? What training will be required for packaging, warehousing and distribution workers? What is the most effective antenna configuration and what characteristics of RF affect the read rate and reliability? The hard science of RFID must come to terms with the environment of shipping radiation sources. Most RFID adopters typically experience problems associated with the following issues: materials translucence and/or absorption, shielding, detuning of the tag antennas, reflection and interference when trying to achieve acceptable performance. RadSTraM was designed to illuminate such problems and identify workaround solutions.

\subsection{PERFORMANCE OBJECTIVES}

This demonstration had the following performance objectives:

1. Validate the performance of RFID intelligent systems to monitor express air shipments of medical radioisotopes in the nationwide supply chain.

2. Quantify the reliability of these tracking systems with regards to probability of tag detection and operational reliability.

3. Determine if the implementation of these systems improves manpower effectiveness.

4. Demonstrate that RFID tracking and monitoring of radioactive materials is ready for large scale deployment at the national level.

\subsection{PHSYCIAL SETUP AND OPERATION}

On February 23, 2006, RFID interrogators were installed at medical radioisotope facility and AE facility in Boston, Massachusetts. The interrogators for AE facility in Knoxville (Alcoa, Tennessee) and ORNL in Oak Ridge, Tennessee were installed on February 28.

The test scenario employed in this project utilized the real world commerce supply chain process for radioactive medical isotopes to validate the performance of RFID intelligent tags. RFID technology was assessed under normal operating conditions, including varied environmental conditions, varied commodities on board vehicles, temporary staging in operating terminals will various commodities and normal transportation handling. The criteria for the test included:

1. U.S. Department of Transportation (DOT) Type A packaged (Figure 12), RFID modified inner containers with electronic inner containers. (The U.S. has four levels of packaging for non-waste radioactive material. Shippers of non-waste radioactive material are affected by three of these packaging levels: strong tight containers (STC), Type A and Type B. STC is used for radioactive materials that have minimal impact on health safety and property should exposure occur. Type A packages are required for transporting material that would have a limited, non-lethal impact on health safety and property. Type B packages are required for transport of radioactive materials that would have a lethal impact on health safety and property should an exposure occur.) 
2. Type A quantities of phosphorus (P-32) package in Type A inner containers, Figure 13.

3. Radioactive material shipments from a medical radioisotope production facility in Massachusetts to ORNL in Roane County, Tennessee using a commercial AE service.

4. Packaging configured with active tags provided by three RFID vendors.

5. Configuration and testing of RFID interrogators provided by the three RFID vendors installed at ORNL, the AE facility in Tennessee, the AE facility in Massachusetts, and the MR production facility in Massachusetts.

6. Collection of data and documentation of results using ORNL's data collection application.

7. Data analysis and lessons learned reporting.

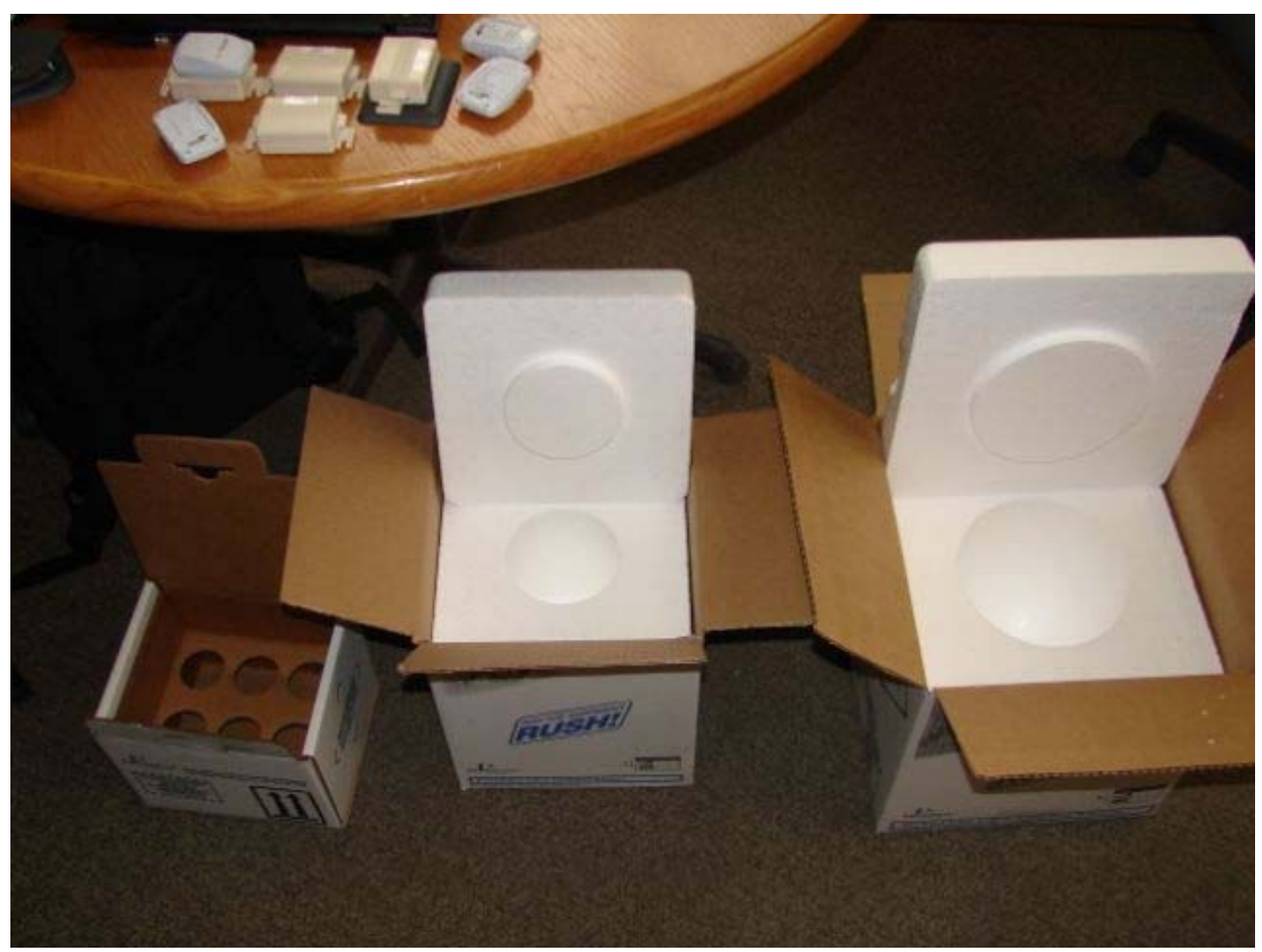

Figure 11. U.S. Department of Transportation (DOT) Type A packages. 


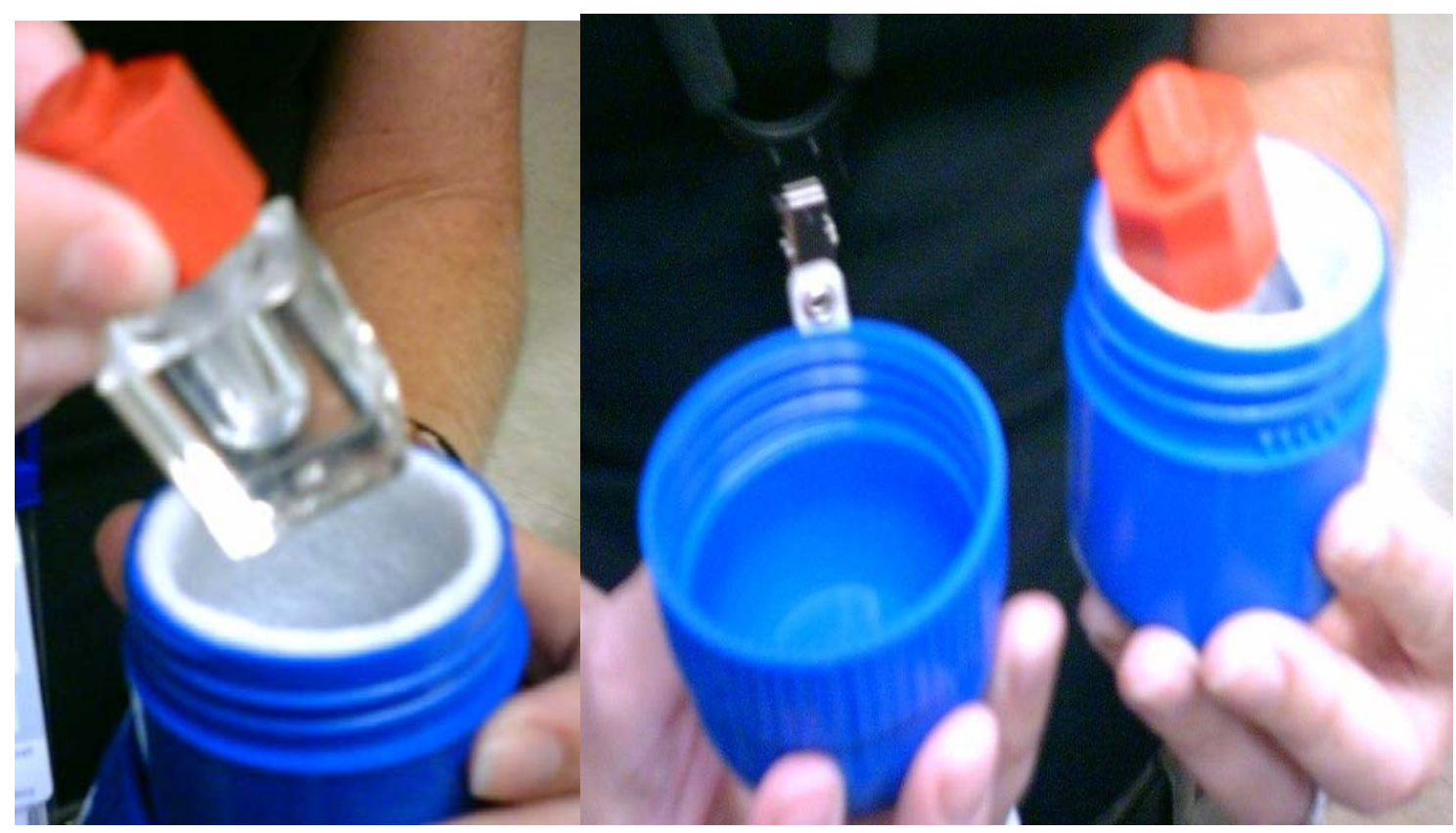

Figure 12. U.S. Department of Transportation (DOT) Type A containers.

Thirty-two air express shipments were tested from May 1, 2006-May 11, 2006. All shipments originated at the medical radioisotope production facility in Boston. The shipments were air expressed to ORNL. From ORNL they were sent back to the medical radioisotope production facility. This round trip route was then repeated. The testing groups were as follows:

1. Three RFID systems: System A, System B and System C.

2. Four tags from each system type (Figure 14) were used for the test. Each tag was tested on two roundtrip shipment runs (medical radioisotope production facility $\rightarrow \mathrm{AE}$ Boston $\rightarrow \mathrm{AE}$ Knoxville $\rightarrow$ ORNL; ORNL $\rightarrow$ AE Knoxville $\rightarrow$ AE Boston $\rightarrow$ medical radioisotope production facility) for a total of four shipments per tag.

3. RFID readers for each system were installed at each point in the route (ORNL, AE Knoxville, AE Boston and MR production facility). Therefore, each tag tested in a shipment should have been seen by a reader eight times per roundtrip.

4. Two tags from each system were tested individually in Type A boxes containing medical radioisotopes. (There were four isotope quantities used in the testing: P32 1mc, P32 500uc, P32 250uc and no radioactive material. Since the medical radioisotopes are all contained within shielded inner containers and the RFID tags are packaged in the boxes outside of the inner containers, the four quantities will be considered as a group in the analysis of the data. See Figure 13 for a picture of the inner containers.)

5. Two tags from each system were tested in the presence of tags from the other two systems in Type A boxes that did not contain medical radioisotopes. (Two subtypes of Type A boxes were used in the testing: Box Type E (small box with six holes) and Box Type A (medium box with one day supply of dry ice). See Figure 12 for pictures of the boxes. Box subtype was not considered in the analysis of the data.)

6. Two shipping conditions: ambient air and dry ice (Figure 15). 


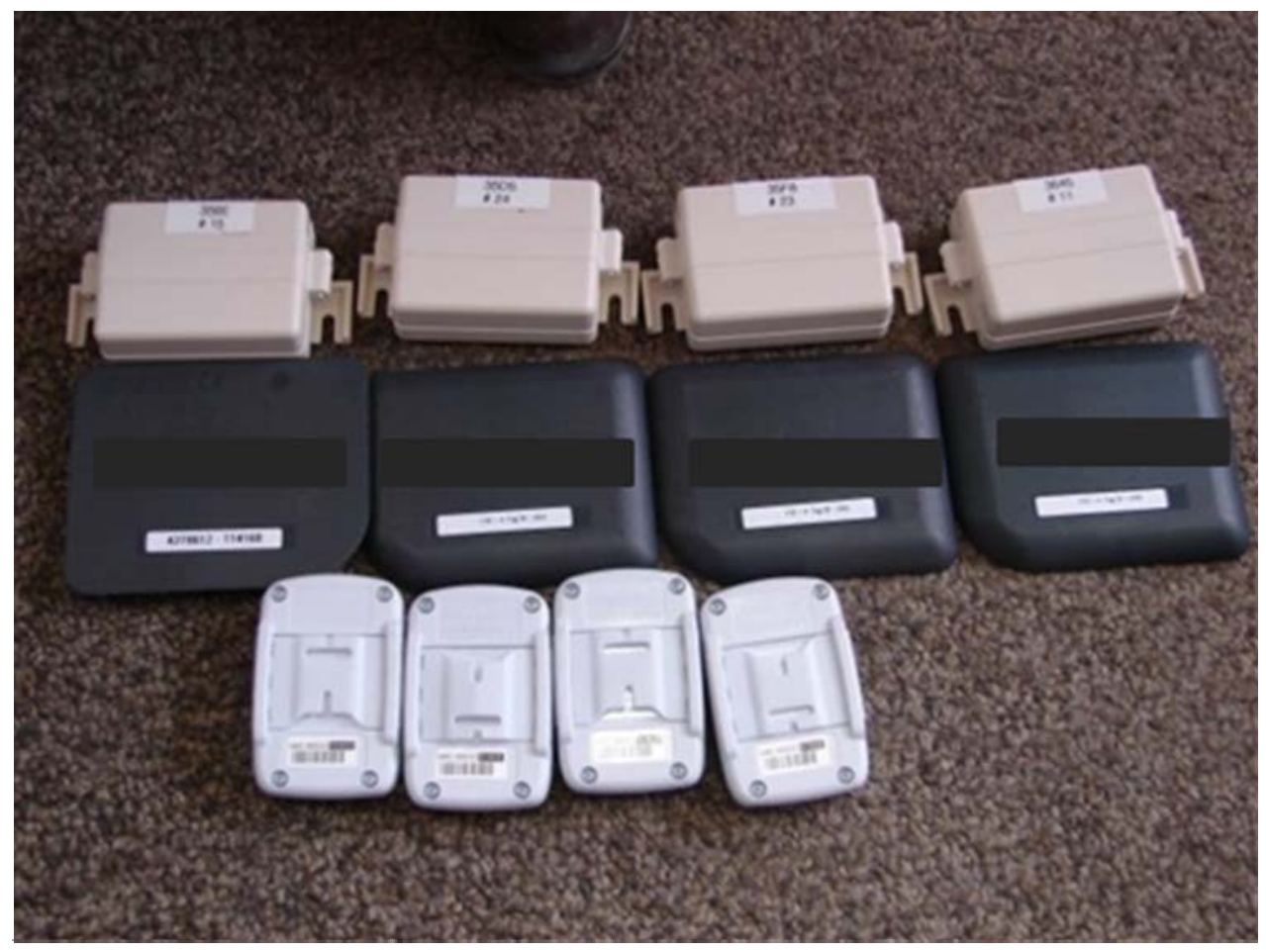

Figure 13. Vendor tags.

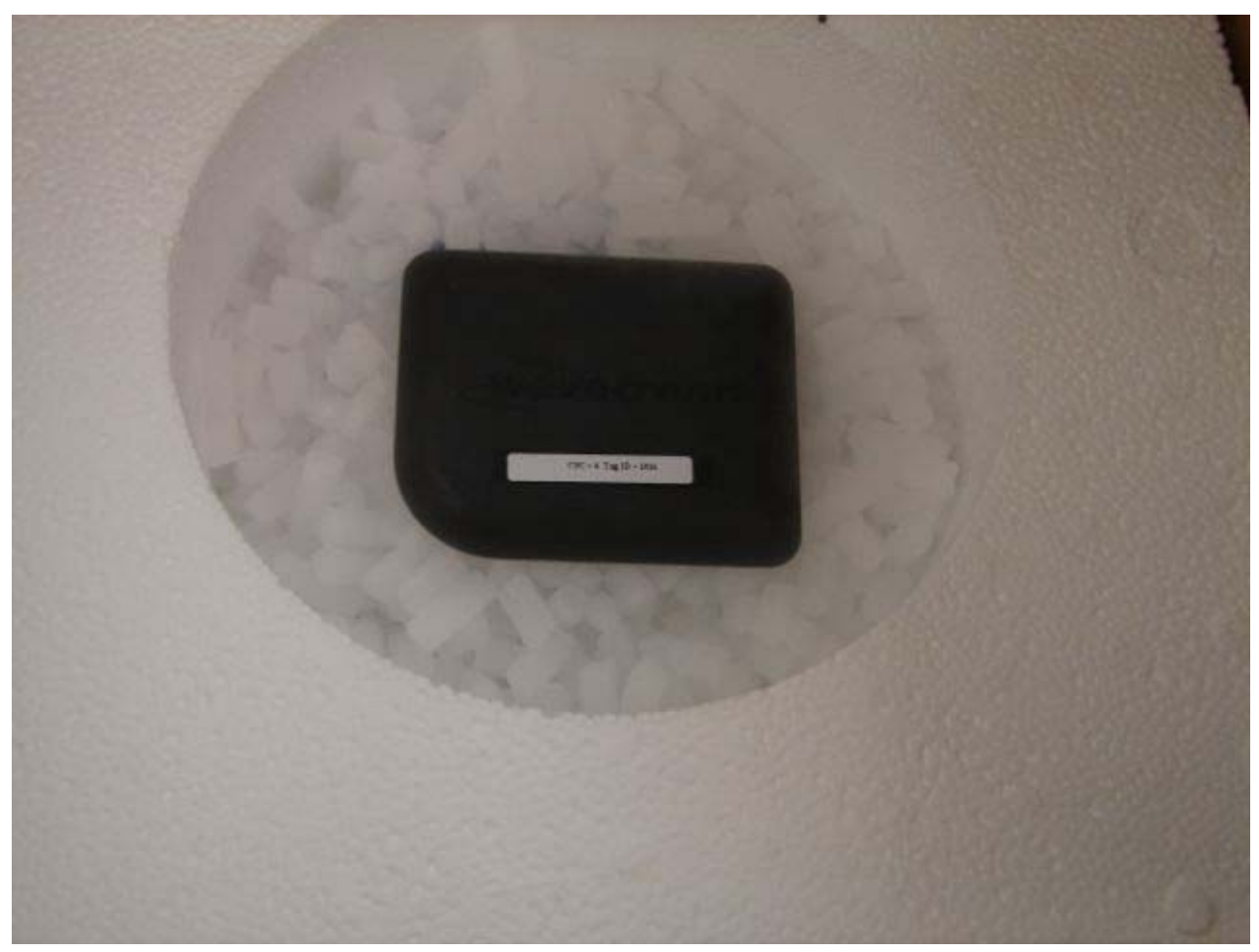

Figure 14. Vendor tags packaged with dry ice. 
Table 1 displays the experimental design.

Table 1. The experimental design

Shipment Runs 1-3

\begin{tabular}{|c|c|c|c|}
\hline \multicolumn{4}{|c|}{ Shipment Runs 1-3 } \\
\hline & Isotope & Shipping & Individual or \\
\hline & Quantity & Condition & Group \\
\hline \multicolumn{4}{|c|}{ System A } \\
\hline Tag A1 & 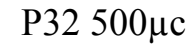 & Ambient & Individual \\
\hline Tag A2 & None & Ambient & Group \\
\hline Tag A3 & P32 $250 \mu \mathrm{c}$ & Dry Ice & Individual \\
\hline Tag A4 & None & Dry Ice & Group \\
\hline \multicolumn{4}{|c|}{ System B } \\
\hline Tag B1 & 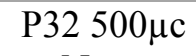 & Ambient & Individual \\
\hline Tag B2 & None & Ambient & Group \\
\hline Tag B3 & P32 1mc & Dry Ice & Individual \\
\hline Tag B4 & None & Dry Ice & Group \\
\hline \multicolumn{4}{|c|}{ System C } \\
\hline Tag C1 & P32 1mc & Ambient & Individual \\
\hline Tag C2 & None & Ambient & Group \\
\hline Tag C3 & P32 1mc & Dry Ice & Individual \\
\hline Tag C4 & None & Dry Ice & Group \\
\hline \multicolumn{4}{|c|}{ Shipment Run 4} \\
\hline & Isotope & Shipping & Individual or \\
\hline & Quantity & Condition & Group \\
\hline \multicolumn{4}{|c|}{ System A } \\
\hline Tag A1 & $\mathrm{P} 32500 \mu \mathrm{c}$ & Ambient & Individual \\
\hline Tag A2 & None & Ambient & Group \\
\hline Tag A3 & P32 $250 \mu \mathrm{c}$ & Ambient & Individual \\
\hline Tag A4 & None & Ambient & Group \\
\hline \multicolumn{4}{|c|}{ System B } \\
\hline Tag B1 & $\mathrm{P} 32500 \mu \mathrm{c}$ & Ambient & Individual \\
\hline Tag B2 & None & Ambient & Group \\
\hline Tag B3 & $\mathrm{P} 321 \mathrm{mc}$ & Ambient & Individual \\
\hline Tag B4 & None & Ambient & Group \\
\hline \multicolumn{4}{|c|}{ System C } \\
\hline Tag C1 & P32 1mc & Ambient & Individual \\
\hline Tag C2 & None & Ambient & Group \\
\hline Tag C3 & P32 1mc & Ambient & Individual \\
\hline Tag C4 & None & Ambient & Group \\
\hline
\end{tabular}

\subsection{TEST PROCEDURES FOR THE MEDICAL RADIOISOTOPE SHIPMENTS}

The general test procedure used is as follows:

1. Package the tags in modified Type A boxes according to its assigned test condition (see Table 1).

2. $\quad$ Assign a RadSTraM shipment number to each package.

3. Scan MR production facility's freight papers, Figure 16. 
4. Scan AE shipping papers, Figure 17.

5. Fill out a new shipment form on ORNL's RFID manifest interface to record the System tag number, the MR production facility's delivery number, the AE tracking number, the isotope quantity, the shipping condition, the box type and the RadSTraM shipment number.

6. Take a digital picture of the package box before it is shipped, Figure 17.

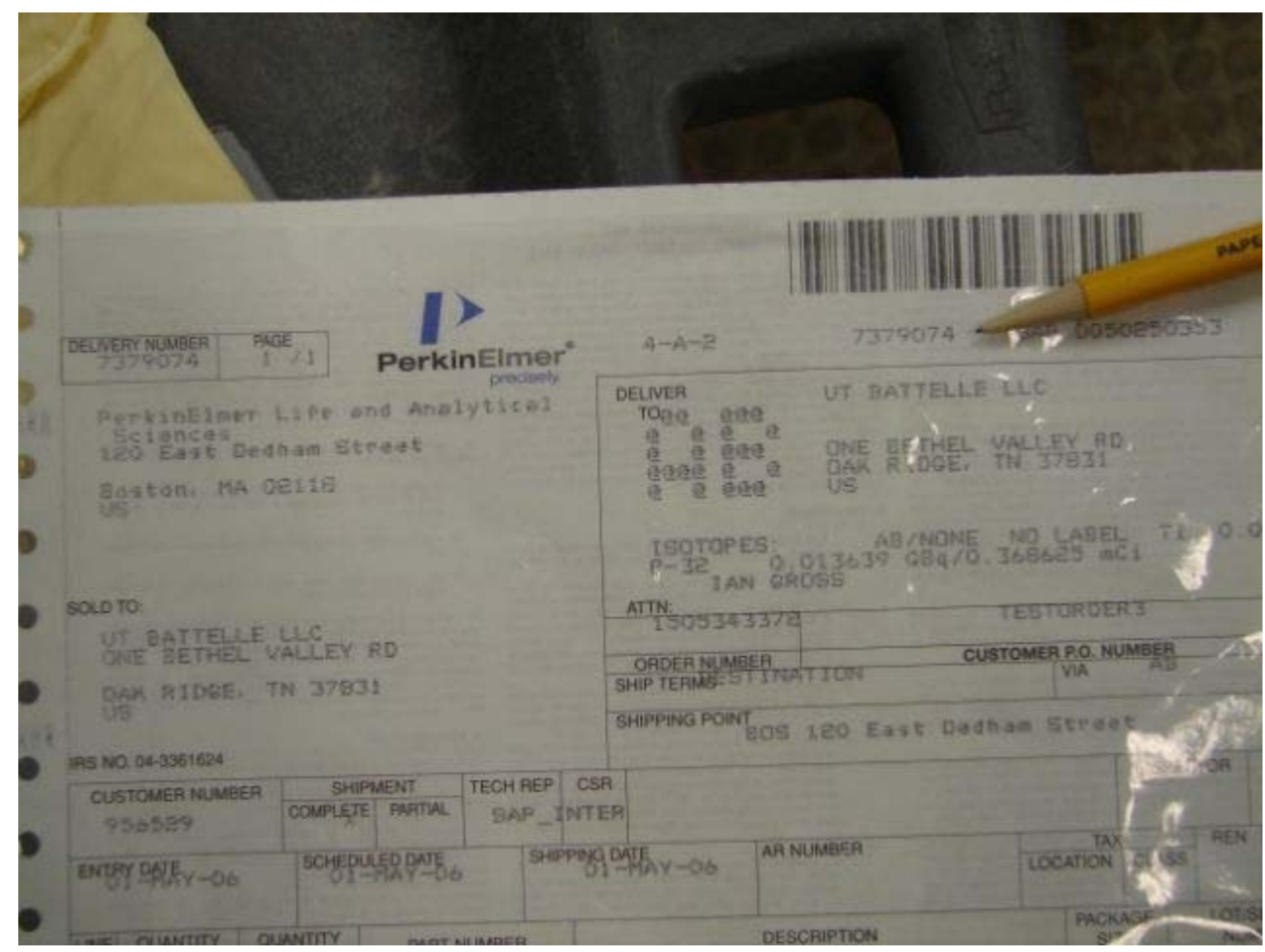

Figure 15. Medical Radioisotope vendor freight paper. 


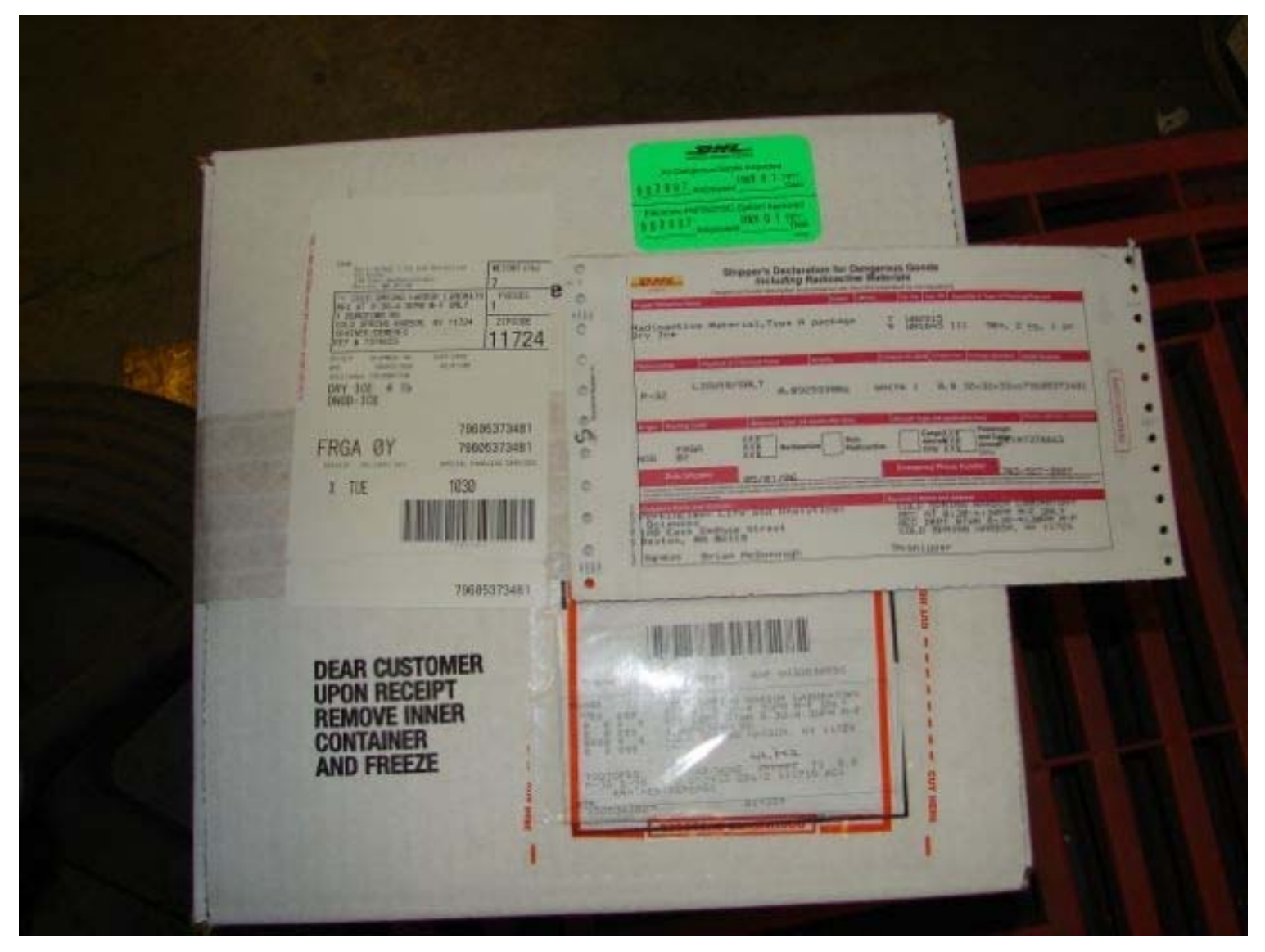

Figure 16. Air Express company shipping papers. 


\section{RESULTS}

Table 2 displays the overall success rate for each system.

\begin{tabular}{|r|r|r|}
\hline \multicolumn{4}{|c|}{ Table 2. The overall success rate } \\
\hline & Ratio of Hits & Percentage of Success \\
\hline System A & $49 / 64$ & $76.56 \%$ \\
\hline System B & $13 / 64$ & $20.3 \%$ \\
\hline System C & $48 / 64$ & $75 \%$ \\
\hline
\end{tabular}

Two-sample $\mathrm{z}$ tests for the significance of the difference between two independent proportions were conducted to determine whether the overall success rates of the RFID systems were significantly different from each other. The overall success rate for each system was $76.56 \%$ (49 out of 64 hits) for System A, $20.3 \%$ (13 out of 64 hits) for System B and 75\% (48 out of 64 hits) for System C. The difference between System A and System B was significant $(z=6.367, p<0.002)$ and the difference between System C and System B was significant $(z=6.194, p<0.002)$. (Sample sizes for the other conditions were too small to satisfy the standard binomial requirement that $n(p)$ and $n(1-p)$ both be greater than or equal to five, where $\mathrm{n}$ is the number of observations and $\mathrm{p}$ is the proportion. Because of this, no statements of significance can be drawn about between or within groups for the ambient air vs. dry ice condition the presence of other tags condition.) Table 3 displays the results for the success rate of shipments package with dry ice compared to those packaged without dry ice for all tags. Dry ice appears to negatively affect the performance of System C. Table 4 displays success rates of tags package in the presence of other tags. Again, dry ice appears to negatively affect the performance of System C. Table 5 displays success rates for tags packaged individually with medical radioisotopes with and without dry ice. The results in Table 5 show that performance of System $C$ appears to be negatively affected by dry ice. The success rates for tags packaged individually and the success rates for tags packaged in the presence of other tags appear to be approximately the same, indicating the performance of these systems is not affected by the presence of other systems.

Table 3. Ambient air vs. dry ice comparison of success rates for each system

\begin{tabular}{|c|c|c|c|c|}
\hline & $\begin{array}{c}\text { Ratio of Hits } \\
\text { Ambient Air }\end{array}$ & $\begin{array}{c}\text { Percentage } \\
\text { of Success }\end{array}$ & $\begin{array}{c}\text { Ratio of Hits } \\
\text { Dry Ice }\end{array}$ & $\begin{array}{c}\text { Percentage } \\
\text { of Hits }\end{array}$ \\
\hline System A & $30 / 40$ & $75 \%$ & $19 / 24$ & $79.2 \%$ \\
\hline System B & $8 / 40$ & $20 \%$ & $5 / 24$ & $20.8 \%$ \\
\hline System C & $36 / 40$ & $90 \%$ & $12 / 24$ & $50 \%$ \\
\hline
\end{tabular}

Table 4. Ambient air vs. dry ice comparison of success rates for each system in the presence of other tags condition

\begin{tabular}{|c|c|c|c|c|}
\hline & $\begin{array}{c}\text { Ratio of Hits } \\
\text { Ambient Air }\end{array}$ & $\begin{array}{c}\text { Percentage } \\
\text { of Success }\end{array}$ & $\begin{array}{c}\text { Ratio of Hits } \\
\text { Dry Ice }\end{array}$ & $\begin{array}{c}\text { Percentage } \\
\text { of Hits }\end{array}$ \\
\hline System A & $13 / 20$ & $65 \%$ & $10 / 12$ & $83.3 \%$ \\
\hline System B & $5 / 20$ & $25 \%$ & $3 / 12$ & $25 \%$ \\
\hline System C & $18 / 20$ & $90 \%$ & $9 / 12$ & $75 \%$ \\
\hline
\end{tabular}


Table 5. Comparison of each system's success rates for shipments packaged with P32 medical radioisotopes

\begin{tabular}{|c|c|c|c|c|c|c|c|c|}
\hline & $1 \mathrm{mc}$ & $\begin{array}{l}\text { Percent } \\
\text { of Hits }\end{array}$ & $\begin{array}{r}500 \\
\mu c\end{array}$ & $\begin{array}{c}\text { Percent } \\
\text { of Hits }\end{array}$ & $\begin{array}{l}250 \\
\mu c\end{array}$ & $\begin{array}{l}\text { Percent } \\
\text { of Hits }\end{array}$ & $\begin{array}{c}\text { All } \\
\text { Quantities }\end{array}$ & $\begin{array}{c}\text { Percent } \\
\text { of Hits }\end{array}$ \\
\hline \multicolumn{9}{|l|}{ System A } \\
\hline $\begin{array}{l}\text { Ambient } \\
\text { Air }\end{array}$ & & & $\begin{array}{c}13 / 1 \\
6\end{array}$ & $81.25 \%$ & $4 / 4$ & $100 \%$ & $17 / 20$ & $85 \%$ \\
\hline $\begin{array}{l}\text { Dry } \\
\text { Ice }\end{array}$ & & & & & $9 / 12$ & $75 \%$ & $9 / 12$ & $75 \%$ \\
\hline \multicolumn{9}{|l|}{ System B } \\
\hline $\begin{array}{c}\text { Ambient } \\
\text { Air }\end{array}$ & $1 / 4$ & $25 \%$ & $2 / 16$ & $16.67 \%$ & & & $3 / 20$ & $15 \%$ \\
\hline $\begin{array}{c}\text { Dry } \\
\text { Ice }\end{array}$ & $2 / 12$ & $16.67 \%$ & & & & & $2 / 12$ & $16.67 \%$ \\
\hline \multicolumn{9}{|l|}{ System C } \\
\hline $\begin{array}{c}\text { Ambient } \\
\text { Air }\end{array}$ & $\begin{array}{c}18 / 2 \\
0\end{array}$ & $90 \%$ & & & & & $18 / 20$ & $90 \%$ \\
\hline $\begin{array}{l}\text { Dry } \\
\text { Ice }\end{array}$ & $3 / 12$ & $25 \%$ & & & & & $3 / 12$ & $25 \%$ \\
\hline
\end{tabular}

\subsection{OBSERVATIONS}

Two incidents occurred during the shipment runs that are important to note.

1. Technical difficulties with system B's server were identified during the first shipment run. The tags were packaged at the medical radioisotope production facility in Boston with all supporting documentation recorded. ORNL's server and System B's server recognized the tags at the Boston facility. When the shipments arrived at ORNL's facility the tags were not recognized by the readers. The batteries in the tags were still working properly, so battery life was determined not to be the problem. ORNL's server was still reading tags from the other vendors, so ORNL's server was not the problem. (ORNL's server obtained data from System B's server, see section 1.3 for details.) Vendor B was able to get their server back on-line, but the reason for the interruption was not identified.

2. During the return shipment of the first run (ORNL to Boston) a package was misplaced. The package contained a tag from Vendor A. The package left the ORNL facility with all the other packages that were part of the shipment. All the appropriate documentation was recorded and ORNL's server registered the tag. When the packages arrived at the AE facility in Knoxville, one of the packages was not scanned by the AE company. When the shipment arrived in Boston the AE company did not have a record of the misplaced package leaving Knoxville. We were able look up the tag that was in the missing package using ORNL's API. We found that the package had been shipped and was at the Boston facility. 


\section{DISCUSSION}

This section contains summary conclusions and lessons learned for Phase II of the RadSTraM project.

\subsection{SUMMARY}

This demonstration tracked 32 air express shipments from a medical radioisotope production facility in Boston, Massachusetts to ORNL in Oak Ridge, Tennessee. Three RFID systems were evaluated under a number of conditions. Each RFID system was individually tested in Type A modified boxes with differing quantities of P32 $(1 \mathrm{mc}, 500 \mu \mathrm{c}$ and $250 \mu \mathrm{c}) 16$ shipments per system. Three of these shipments per system contained dry ice. An additional 16 shipments were tested that contained one tag from each system packaged Type A boxes without P32. Twelve of these shipments contained dry ice. RFID interrogators for each system were installed at four waypoints along the shipping route: the medical radioisotope production facility in Boston, Massachusetts, the AE terminal at Logan International Airport in Boston, Massachusetts, the AE terminal at McGhee Tyson International Airport in Knoxville, Tennessee and ORNL in Oak Ridge, Tennessee. Each package was expected to be detected by its corresponding interrogator(s) four times per shipment.

System A's overall probability of detection was 76.56 percent, System B's overall probability of detection was 20.3 percent and System C's overall probability was 75 percent. Results for System A's and System C's overall probability of detection were found to be significantly higher than System B's. The presence of more than one RFID system in a shipment did not appear to have an effect on any the three systems tested. However, no tests of significance could be performed because between and within group sample sizes did not satisfy the standard binomial requirement for the test of significant difference between independent proportions. The presence of dry ice appeared to have a deleterious effect on System C, but again sample sizes did not satisfy the standard binomial requirement for test of significant difference between independent proportions and conclusions cannot be drawn for these results.

\subsection{LESSONS LEARNED}

Table 6 displays how Phase II implemented Phase I procedural lessons learned.

\begin{tabular}{|l|l|}
\hline \multicolumn{2}{|c|}{ Table 6. Implementation of Phase I lessons learned in Phase II of Testing } \\
\hline \multicolumn{1}{|c|}{ Phase I Lesson Learned } & \multicolumn{1}{c|}{ Phase II Implementation } \\
\hline $\begin{array}{l}\text { A standard form should be designed that } \\
\text { includes all relevant information. }\end{array}$ & $\begin{array}{l}\text { ORNL's web-based RFID manifest system } \\
\text { contains a standard form on its user interface. }\end{array}$ \\
\hline $\begin{array}{l}\text { More attentions should be given to completing } \\
\text { forms in their entirety. }\end{array}$ & $\begin{array}{l}\text { A protocol for collecting data was implemented } \\
\text { that included completely filling forms. }\end{array}$ \\
\hline $\begin{array}{l}\text { Shipments should be verified as going through } \\
\text { each waypoint. }\end{array}$ & $\begin{array}{l}\text { Collaborating with a national air express } \\
\text { shipper provided a secondary check of through } \\
\text { the use of their shipment tracking software. }\end{array}$ \\
\hline $\begin{array}{l}\text { Software should automatically run when a } \\
\text { system reboots. }\end{array}$ & $\begin{array}{l}\text { New software designed to automatically } \\
\text { reboot. }\end{array}$ \\
\hline $\begin{array}{l}\text { Data should be handled in electronic form to } \\
\text { reduce human error. }\end{array}$ & $\begin{array}{l}\text { ORNL's web-based RFID manifest system was } \\
\text { developed to reduce the error seen with hand } \\
\text { written test logs. }\end{array}$ \\
\hline $\begin{array}{l}\text { All data should be copied to a single database } \\
\text { for storage and analysis. }\end{array}$ & $\begin{array}{l}\text { ORNL's web-base RFID manifest system } \\
\text { stores all of the test data in a database. }\end{array}$ \\
\hline
\end{tabular}


Phase II of the RadSTraM project successfully implemented the lessons learned from Phase I. Human error seen in data logging in Phase I were eliminated in Phase II by the use of a web-based manifest system to standardized the data entry forms. Implementing a protocol for collecting test data helped to eliminate errors in data logging. Using the web-base manifest system to collect and store data increased the manageability of the data and provided a user-friendly graphical interface that could be accessed by a variety of users. The results of the shipping runs in Phase II indicate that the use of dry ice in shipments of medical radioisotopes does decrease the performance of some types of tags. However, operating tags from multiple vendors in close proximity of each other does not appear to affect their performance.

\subsection{CONCLUSIONS}

Phase II of the RadSTraM project verified that RFID tagging can be applied to the tracking and monitoring of medical radioisotope air express shipments. The project demonstrated that active RFID tagging systems are robust and mature enough to be scaled into the nation-wide supply chain for medical radioisotopes. The development of a web-base manifest system by ORNL to handle data eliminated the problems with data handling reported in Phase I of the RadSTraM project. 


\section{REFERENCES}

1. Sheldon, F.T., Walker, R.M. and Abercrombie, R.K. "RadSTraM: Radiological Source Tracking and Monitoring, Interim Final Report," June, 2003.

2. IAEA, Training Course Series Number On, Safe Transport of Radioactive Materials, $3^{\text {rd }}$ edition, Vienna, Austria.

3. U.S. General Accounting Office, Nuclear Nonproliferation; U.S. and International Assistance Efforts to Control Sealed Radioactive Sources Need Strengthening, GAO-03-638, May 2003.

4. Bolton, John R., "Under Secretary for Arms Control and International Security: Keynote Address," International Approaches to Nuclear and Radiological Security Conference, London, (available at http://www.state.gov/t/us/rm/14064.htm), Sept. 30, 2002.

5. IAEA, "Inadequate Control of World's Radioactive Sources," IAEA Press Release, (available at http://hps.org/documents/iaeapressrelease.pdf), June 24, 2002.

6. Kopsick, D., Hamlin, s. and Rae, R., "Preventing Exposure to Orphan Radioactive Sources," (available at http://www.crcpd.org/AnnualMeeting-03/2003\%20Presentation\%20Texts/05071155 Kopsicktxt.pdf), March 2003. 
Appendix A

GENERAL RFID SYSTEM OVERVIEW 



\section{Appendix A. GENERAL RFID SYSTEM OVERVIEW}

A typical RFID system consists of four main components: tags, an encoder, readers and a host computer (not including the Internet). The last three components can be configured as independent units or combined in one total package (portable or fixed). The RFID tag is made up of a microchip and a flexible antenna encased in a plastic-coated inlay (or wrapper). The encoder is used to write information to the tag. RFID tags are expected to be built into most products and product packaging in the near future. The most common format is a shipping label with a built-in tag, or smart label. Smart labels can be printed and placed on any unit to be tracked. Tags for supply chain use come in a few basic types. One distinguishing characteristic is whether a tag is active or passive. Active RFID tags broadcast under their own power. An on-board battery runs the tag's microchip circuitry and transmitter. Active tags are capable of receiving and transmitting signals the distance of 100 yards. They are well suited to applications where they can be permanently mounted and maintained such as on trucks, railroad cars or shipping containers (possibly sea borne), and on high-value military items stored in outdoor supply depots or bases. Passive tags, in contrast, have no battery and draw their power from the listener. Electromagnetic waves transmitted from the listener induce a current in the tag's antenna. The tag uses that energy to talk back to the listener (i.e., backscatter reflection). The phenomenon is similar to radar. Whereas radar backscatter is more like an echo, the tiny circuit in an RFID tag can power itself with the induced current, and its backscatter is an amplitude modulated response (i.e., the amplitude modulated signal can be interpreted as a digital signal of ones and zeros). When these tags are not in the presence of a listener signal directed at them, passive tags are not capable of transmitting a radio signal. Therefore, they do not add unnecessary electromagnetic noise to the surroundings. Another type of tag is the semipassive tag. It has many of the characteristics of a passive tag (small, lightweight, limited memory), but with a battery backup to extend the answer range. Semi-passive tags are becoming more popular for parts kitting and just in time manufacturing applications.

The distance a reader can communicate with a tag is called the read range. Communications between readers and tags are governed by protocols and emerging standards such as the EPC UHF Class 1 standard for supply chain applications. The properties of radio waves are frequency dependent. At low frequencies radio waves pass through obstacles well, but the power falls off sharply with distance from the source. At high frequencies radio waves tend to travel in straight lines and bounce off obstacles. They diffract at corners, sharp edges and openings. They are also subject to interference from a variety of

sources, from sunspots to other electrical equipment. Radio communications have uses in all sorts of applications, but only if interference between users can be kept at a minimum. For this reason, governments tightly license users of radio transmitters, with the exception of the industrial, scientific and medical (ISM) bands. Transmitters using these bands do not require government licensing. One band, 2.400-2.484 GHz, is allocated worldwide. The United State and Canada have also allocated two bands, 866-956 MHz and 5.725-5.850 GHz, for cordless telephones, garage door openers, wireless hi-fi speakers, security gates, etc.

Adopters of RFID systems must protect their investments during implementation by seeking out upgradeable devices that will retain their usefulness through the lab, pilot and production phases of an implementation. Devices that are engineered for rugged use in a production environment from suppliers with a proven industry experience and a commitment to helping bootstrap their customer base will certainly be the most desirable. Device vendors should provide software migration tools that support the conversion of the current state of practice over to the use of RFID systems. Furthermore, as the single biggest cost item, users need flexibility in sourcing tags. Vendors who offer tag compliance and certification services, and professional service teams who will help users to achieve compliance are the most desirable. Vendor teams who have RFID and supply chain experience working together on similar 
projects offer the best assurance of success for the move toward volume production with respect to system integration and success. It will be important to find teams who have the ability to work with both legacy systems and open-source languages and protocols to ensure against having to scrap a system and start over. Finally, smart labels with bar coding offer the best way to identify and disaster recover from RFID problems. Users should look for ways to stream RFID into the current bar coding processes, and partners that will help retain the integrity of both systems for the foreseeable future. 



\section{INTERNAL DISTRIBUTION}
1. R. K. Abercrombie
2. I. G. Gross
3. D. E. Hill
4. C. M. Smith
5. F. T. Sheldon
6. J. P. Trien
7. R. M. Walker
8. T. A. Warren
9. B. A. Worley
10. Central Research Library
11. ORNL Laboratory Records-RC
12. ORNL Laboratory Records-OSTI 